\title{
Dopamine D2 receptor antagonist sulpiride enhances dexamethasone responses in the treatment of drug- resistant and metastatic breast cancer
}

\author{
Jian $\mathrm{LI}^{2}$, Qing-yu YAO ${ }^{2}$, Jun-sheng XUE², Li-jie WANG ${ }^{2}$, Yin YUAN² ${ }^{2}$ Xiu-yun TIAN ${ }^{3}$, Hong SU², Si-yuan WANG ${ }^{2}$, Wen-jun $\mathrm{CHEN}^{2}$, \\ Wei $\mathrm{LU}^{1,2, *}$, Tian-yan $\mathrm{ZHOU}^{1,2, *}$ \\ ${ }^{1}$ Beijing Key Laboratory of Molecular Pharmaceutics and New Drug Delivery Systems, School of Pharmaceutical Sciences, Peking \\ University, Beijing 100191, China; ${ }^{2}$ Department of Pharmaceutics, School of Pharmaceutical Sciences, Peking University Health \\ Science Center, Beijing 100191, China; ${ }^{3}$ Key Laboratory of Carcinogenesis and Translational Research (Ministry of Education/Beijing), \\ Department of Hepato-Pancreato-Biliary Surgery, Peking University Cancer Hospital \& Institute, Beijing 100142, China
}

\begin{abstract}
Recent evidence shows that dopamine D2-like receptor (D2DR) antagonists, such as trifluoperazine and thioridazine, are effective for cancer therapy and inhibition of cancer stem-like cells (CSCs). In this study, we investigated the anti-cancer effects of combination therapy of dexamethasone (DEX) and sulpiride (SUL), an atypical antipsychotic, against drug-resistant and metastatic breast cancers and further explored the underlying mechanisms. Oral administration of SUL $\left(25,100 \mathrm{mg} \cdot \mathrm{kg}^{-1} \cdot \mathrm{d}^{-1}\right)$ alone did not inhibit the tumor growth in human breast cancer MCF-7/Adr xenograft model, but dose-dependently decreased the proportion of CSCs in vitro and in vivo. In contrast, combination therapy of SUL (50 $\left.\mathrm{mg} \cdot \mathrm{kg}^{-1} \cdot \mathrm{d}^{-1}\right)$ and DEX ( $8 \mathrm{mg} \cdot \mathrm{kg}^{-1} \cdot \mathrm{d}^{-1}$ ) markedly suppressed the tumor growth in MCF-7/ Adr xenograft model with little systemic toxicity and lung metastasis in murine metastatic breast cancer 4T1 xenograft model. Among the metastasis-associated biomarkers analyzed, the combination therapy significantly decreased the levels of MMP-2, but increased E-cadherin levels in 4T1 xenograft tumors. Moreover, the combination therapy significantly inhibited the cell colony formation, migration and invasion of 4T1 and human breast cancer MDA-MB-231 cells in vitro. Addition of a specific D2DR agonist 7-OH-DPAT to the combination therapy reversed the enhanced anti-cancer effects in vivo and CSC population loss in tumor tissues. Our data demonstrate that SUL remarkably enhances the efficacy of DEX in the treatment of drug-resistant and metastatic breast cancer via the antagonism of D2DR, which might result from the eradication of CSCs.
\end{abstract}

Keywords: breast cancer; dexamethasone; sulpiride; dopamine-D2 receptor; combination therapy; drug-resistance; metastasis; cancer stem cells; 7-OH-DPAT

Acta Pharmacologica Sinica (2017) 38: 1282-1296; doi: 10.1038/aps.2017.24; published online 26 Jun 2017

\section{Introduction}

Breast cancer is the most common malignancy and the second leading cause of cancer death among women ${ }^{[1]}$. In clinics, endocrine therapy, cytotoxic chemotherapy, and biologic therapy are the most commonly used systemic managements for breast cancer patients ${ }^{[2]}$. However, some tumors do not respond or become resistant to these therapies, resulting in subsequent drug resistance ${ }^{[3]}$ and metastasis ${ }^{[4]}$. Drug resistance and metastasis are the most malignant and dangerous characteristics of breast cancer ${ }^{[4,5]}$, and these are the most

\footnotetext{
${ }^{*}$ To whom correspondence should be addressed.

E-mail tianyanzhou@bjmu.edu.cn (Tian-yan ZHOU); luwei_pk@bjmu.edu.cn (Wei LU)

Received 2016-10-25 Accepted 2017-02-04
}

important scientific issues that need to be solved in breast cancer chemotherapy.

Dexamethasone (DEX) is a synthetic glucocorticoid that is frequently used in the clinic. Several published studies have demonstrated the anti-cancer effects of DEX as a single agent $^{[6-11]}$. For estrogen receptor positive (ER+) breast cancer, DEX can significantly antagonize the systemic estrogens by the glucocorticoid receptor-mediated activation of estrogen sulfotransferase, which results in inhibition of breast cancer ${ }^{[8]}$. In addition, DEX suppresses cancer cell invasion and metastasis through its potent anti-inflammatory effects ${ }^{[9]}$, the elevation of metastasis suppressor gene expression ${ }^{[10]}$, and the suppression of matrix metalloproteinase-2 (MMP-2) secretion ${ }^{[11]}$. However, the response of drug-resistant and metastatic breast cancer to DEX alone is relatively weak and could be further improved 
in combination with other agents ${ }^{[7]}$.

Recently, it was demonstrated that the dopamine D2-like receptor (D2DR) antagonist trifluoperazine could overcome the drug resistance of cancer cells when combined with either gefitinib or cisplatin, and it enhanced the inhibitory activity of gefitinib in lung cancer metastatic animal models by targeting cancer stem-like cells (CSCs $)^{[12]}$. In addition, thioridazine, another D2DR antagonist, was also reported to be effective for cancer therapy and CSC inhibition ${ }^{[13,14]}$. Based on these reports, we speculated that sulpiride (SUL), an atypical antipsychotic with good efficacy and few side effects in the clinical treatment of schizophrenia ${ }^{[15,16]}$, might also be an adjuvant agent for cancer therapy because of its specific antagonism of D2DR. To the best of our knowledge, there is no report referring to the anti-cancer effects of SUL or SUL combined with other agents. Moreover, SUL and DEX are not currently used alone as anti-cancer drugs. However, because SUL and DEX are commonly used in the clinic, their toxicities are tolerable for patients, and the costs are low; therefore, it would be of great benefit for cancer patients if SUL and DEX could be used in combination therapy. This prompted us to investigate the anti-cancer effects of the combination of SUL and DEX with the expectation of improved outcomes in drug-resistant and metastatic breast cancer. Thus, the aim of this study was to investigate the anti-cancer effects of SUL combined with DEX and the toxicities of the combination therapy in the treatment of drug-resistant and metastatic breast cancer.

\section{Materials and methods}

\section{Chemicals and antibodies}

Sulpiride and dexamethasone were purchased from SigmaAldrich, MO, USA. 7-Hydroxy-DPAT $\cdot \mathrm{HBr}$ was obtained from Santa Cruz Biotechnology, Inc, TX, USA. Epirubicin and hydroxypropyl- $\beta$-cyclodextrin were purchased from Melone Pharmaceutical Co, Ltd, Dalian, China. Anti-CD44-FITC, anti-CD24-PE, and the isotype controls were purchased from Abcam, Cambridge, UK. Other chemicals were purchased from Beijing Chemical Works, Beijing, China.

\section{Cell culture}

Murine metastatic breast cancer 4T1 cells and human breast cancer MCF-7/Adr and MDA-MB-231 cells were obtained from the Institute of Materia Medica, Academy of Medical Sciences, Beijing, China. RPMI-1640 medium supplemented with $10 \%$ fetal bovine serum (FBS) was used to culture $4 \mathrm{~T} 1$ cells and MCF-7/Adr cells (Gibco, NY, USA) at $37^{\circ} \mathrm{C}$ in a $5 \% \mathrm{CO}_{2}$ atmosphere. MDA-MB-231 cells were cultured in Leibovitz's L-15 medium supplemented with $10 \% \mathrm{FBS}$ at $37^{\circ} \mathrm{C}$ in an atmosphere without $\mathrm{CO}_{2}$. In this study, MCF-7/Adr cells were selected as the drug-resistant breast cancer cells, and 4T1 cells and MDA-MB-231 cells were selected as the metastatic breast cancer cells.

\section{Animals}

Female nu/nu nude mice weighing 18-22 g (4-5 weeks old) were obtained from Vital River (Beijing, China) and housed in standard conditions of $50 \%-60 \%$ humidity at $22-24^{\circ} \mathrm{C}$ with $12 \mathrm{~h} / 12 \mathrm{~h}$ light/dark cycles and given free access to food and water before being used in the study.

All the animal procedures in this study were approved by the Institutional Animal Care and Use Committee of Peking University Health Science Center.

\section{Anti-cancer efficacy in the drug-resistant breast cancer xenograft model}

MCF-7/Adr cells $\left(2 \times 10^{6}\right.$ cells suspended in $200 \mu \mathrm{L}$ of FBS-free medium) were subcutaneously injected into mice to establish an orthotopic breast cancer xenograft model. At approximately $\mathrm{d} 5$, the mice were randomly divided into the following different treatment groups $(n=5)$ : (a) control group: vehicle solutions were administered daily; (b) epirubicin group: epirubicin, which was selected as the positive control ${ }^{[17]}$, was dissolved in normal saline and injected every three days at $4 \mathrm{mg} / \mathrm{kg}$; (c) SUL groups: SUL was dissolved in $45 \%(w / v)$ hydroxypropyl- $\beta$-cyclodextrin aqueous solution and orally administered daily at 25 or $100 \mathrm{mg} / \mathrm{kg}$; (d) DEX groups: DEX was dissolved in corn oil and orally administered daily at 1 , 2, or $8 \mathrm{mg} / \mathrm{kg}$; and (e) SUL+DEX groups: SUL and DEX were concurrently administered daily at different combination dosages. The tumor diameters were measured using calipers, and the tumor volumes were calculated by the following formula: tumor volume $\left(\mathrm{mm}^{3}\right)=0.5 \times \mathrm{A} \times \mathrm{B}^{2}$, where A represents the larger diameter and $\mathrm{B}$ represents the smaller diameter of the tumor.

All the drugs in the combination groups were simultaneously administered. The body weights of different groups were recorded every other day and used as indicators of systemic toxicity. After treatment for $18 \mathrm{~d}$, the mice were euthanized. Tissues and whole blood in high dose groups and the tumors in all the groups were harvested for later assessments.

Subsequently, to further investigate the mechanisms of SUL activity, 7-OH-DPAT, a specific D2DR agonist ${ }^{[13]}$, was dissolved in normal saline and administered intratumorally daily at $1 \mathrm{mg} / \mathrm{kg}$ either alone or in combination with SUL+DEX. The tumor volumes were measured daily, and tumor tissues were harvested and photographed after $18 \mathrm{~d}$ of treatment.

\section{Toxicity analysis of the combination therapy H\&E staining of main organs}

Harvested tissues from MCF-7/Adr xenograft mice were fixed with formalin, embedded in paraffin wax, sliced and mounted on slides before being stained with hematoxylin and eosin to evaluate morphological changes.

\section{Blood tests}

Whole blood samples were collected from the postorbital venous plexus of MCF-7/Adr xenograft mice. Then, $20 \mu \mathrm{L}$ of blood was added to $2 \mathrm{~mL}$ of diluent solution and loaded into a MEK-6318K Hematology Analyzer (Nihon Kohden, Tokyo, Japan).

\section{Colony formation assays}

MCF-7/Adr, 4T1, and MDA-MB-231 cells were seeded in six- 
well plates (1500 cells per plate) and treated with $1 \%(v / v)$ DMSO, $50 \mu \mathrm{mol} / \mathrm{L}$ SUL, $50 \mu \mathrm{mol} / \mathrm{L}$ DEX, $50 \mu \mathrm{mol} / \mathrm{L}$ SUL +50 $\mu \mathrm{mol} / \mathrm{L}$ DEX, $10 \mu \mathrm{mol} / \mathrm{L}$ 7-OH-DPAT, or $50 \mu \mathrm{mol} / \mathrm{L}$ SUL+50 $\mu \mathrm{mol} / \mathrm{L} \mathrm{DEX}+10 \mu \mathrm{mol} / \mathrm{L} 7-\mathrm{OH}-\mathrm{DPAT}$ for $48 \mathrm{~h}$. The cells were then cultured with complete medium lacking drugs for $8 \mathrm{~d}$. The colonies were visualized on an EVOS microscope after fixing with methanol and staining with crystal violet.

\section{Proportions of cancer stem-like cells in vitro and in vivo}

Breast cancer stem-like cells were defined as $\mathrm{CD}_{4} 4^{+} / \mathrm{CD} 24^{-}$ cells ${ }^{[18]}$. To investigate the mechanisms of SUL activity in vitro, MCF-7/Adr cells were cultured in the presence of DMSO (vehicle) and different concentrations of SUL (20, 40, and 50 $\mu \mathrm{mol} / \mathrm{L}$ ) for $48 \mathrm{~h}$. Subsequently, the cells were dissociated, collected, washed twice with PBS, and simultaneously stained with anti-CD44-FITC and anti-CD24-PE or their corresponding isotype controls at $37^{\circ} \mathrm{C}$ for $30 \mathrm{~min}$ in staining buffer (PBS, $\mathrm{pH}$ 7.4). After washing with PBS 3 times, the assay was performed with a FACScan flow cytometer (Becton Dickinson, CA, USA) using previously published procedures ${ }^{[19]}$.

Tumor samples from different treatment groups were collected after the last drug administration. The tumors were minced and digested in $2 \mathrm{~mL}$ of mammary epithelial growth medium (MEGM) with $250 \mathrm{U} / \mathrm{mL}$ of collagenase ${ }^{[20]}$. After incubation at $37^{\circ} \mathrm{C}$ for $4-6 \mathrm{~h}$, the samples were filtered and washed 3 times with Hank's Balanced Salt Solution (HBSS, Invitrogen, CA, USA). Subsequently, the single cells were stained simultaneously with anti-CD44-FITC and anti-CD24$\mathrm{PE}$ or with their corresponding isotype controls at $37^{\circ} \mathrm{C}$ for $30 \mathrm{~min}$ in staining buffer (HBSS). After washing with HBSS 3 times, the assay was performed on the FACScan flow cytometer.

\section{Anti-cancer efficacy in the metastatic breast cancer xenograft model}

To establish an orthotopic metastatic breast cancer model, 4T1 cells $\left(2 \times 10^{6}\right.$ cells suspended in $200 \mu \mathrm{L}$ of FBS-free medium) were subcutaneously injected into mice.

When tumor volume reached approximately $100 \mathrm{~mm}^{3}$, the mice were randomly divided into the following 4 treatment groups ( $n=5$ per group): (a) control group: vehicle solutions were administered daily; (b) SUL group: SUL was dissolved in $45 \%(w / v)$ hydroxypropyl- $\beta$-cyclodextrin aqueous solution and orally administered at $50 \mathrm{mg} / \mathrm{kg}$ daily; (c) DEX group: DEX was dissolved in corn oil and orally administered at 8 $\mathrm{mg} / \mathrm{kg}$ daily; and (d) SUL+DEX group: DEX $(8 \mathrm{mg} / \mathrm{kg})$ was administered concurrently with SUL $(50 \mathrm{mg} / \mathrm{kg})$ daily. After two weeks of treatment, the mice were euthanized. All tumors and lungs were harvested for later assessments.

The lungs in each group were solidified and stained with Bouin's Fluid (Leagene, Beijing, China) and photographed. To evaluate the morphological changes and metastatic tumor cells on lungs, the harvested lungs were embedded in paraffin wax, sliced and mounted on slides before being stained with hematoxylin and eosin (H\&E).

\section{Expression of metastasis-associated biomarkers}

The cytosol of the harvested tumors in each group of the metastatic xenograft nude mice was prepared as previously described $^{[21]}$. The concentrations of the metastasis-associated biomarkers MMP-2, MMP-9, E-cadherin, N-cadherin and claudin1 were measured using commercial ELISA kits according to the manufacturer's instructions.

\section{Wound-healing assays}

4T1 and MDA-MB-231 cells were seeded into 6-well plates. When the monolayer cells covered $90 \%$ of the plates, a linear wound was generated with a $200-\mu \mathrm{L}$ pipette tip, and the cells were then washed with PBS buffer. The cells were cultured in medium supplemented with $2 \%$ FBS for $8-12 \mathrm{~h}$ to monitor wound healing in the presence of $1 \%(v / v)$ DMSO, $50 \mu \mathrm{mol} / \mathrm{L}$ SUL, $50 \mu \mathrm{mol} / \mathrm{L}$ DEX, $50 \mu \mathrm{mol} / \mathrm{L}$ SUL $+50 \mu \mathrm{mol} / \mathrm{L}$ DEX, 10 $\mu \mathrm{mol} / \mathrm{L} 7-\mathrm{OH}-\mathrm{DPAT}$, or $50 \mu \mathrm{mol} / \mathrm{L} \mathrm{SUL}+50 \mu \mathrm{mol} / \mathrm{L} \mathrm{DEX}+10$ $\mu \mathrm{mol} / \mathrm{L}$ 7-OH-DPAT. The images were captured under an EVOS microscope.

\section{Transwell migration and invasion assays}

$4 \mathrm{~T} 1$ cells $\left(3 \times 10^{4}\right.$ in $\left.300 \mu \mathrm{L}\right)$ and MDA-MB-231 cells $\left(5 \times 10^{4}\right.$ in $300 \mu \mathrm{L}$ ) were suspended in FBS-free medium and added to the upper Transwell chambers (Costar 3422, Corning Incorporated Life Sciences, NY, USA) in the presence of $1 \%(v / v)$ DMSO, $50 \mu \mathrm{mol} / \mathrm{L}$ SUL, $50 \mu \mathrm{mol} / \mathrm{L}$ DEX, $50 \mu \mathrm{mol} / \mathrm{L}$ SUL $+50 \mu \mathrm{mol} / \mathrm{L}$ DEX, $10 \mu \mathrm{mol} / \mathrm{L}$ 7-OH-DPAT, or $50 \mu \mathrm{mol} / \mathrm{L}$ SUL $+50 \mu \mathrm{mol} / \mathrm{L}$ $\mathrm{DEX}+10 \mu \mathrm{mol} / \mathrm{L}$ 7-OH-DPAT. Subsequently, $500 \mu \mathrm{L}$ of complete medium (with $10 \%$ FBS) acting as a chemoattractant was added to the lower chambers. The cells were allowed to migrate through the polycarbonate membrane $(8.0 \mu \mathrm{m}$ pore) to the lower chamber. After incubation for $12 \mathrm{~h}$ at $37^{\circ} \mathrm{C}$, the nonmigrated cells on the upper surface of the membrane were scraped with a cotton swab, and the migrated cells on the lower surface were fixed with methanol for $15 \mathrm{~min}$ and stained with crystal violet staining solution ${ }^{[22]}$. The images were captured under an EVOS microscope.

For Transwell invasion assays, the upper transwell chambers were coated with matrigel (BD, NJ, USA), which was previously diluted at a ratio of $1: 8$ with serum-free media. The matrigel solidified for $1 \mathrm{~h}$ at $37^{\circ} \mathrm{C}$ before being used. 4T1 cells $\left(6 \times 10^{4}\right.$ in $\left.200 \mu \mathrm{L}\right)$ and MDA-MB-231 cells $\left(8 \times 10^{4}\right.$ in 200 $\mu \mathrm{L})$ suspended in FBS-free medium were added to the upper chambers in the presence of different drug treatments, and the subsequent procedures were the same as those of the Transwell migration assays.

\section{Statistical analysis}

The results are expressed as the mean \pm SD. Statistical analyses were performed using GraphPad Prism 5.0 software (GraphPad Software, Inc, CA, USA). One-way analysis of variance (ANOVA) was used to determine the significance among different groups followed by post hoc tests with Bonferroni's correction. A value of $P<0.05$ was considered statistically significant. 


\section{Results}

The effects of the combination therapy on drug-resistant breast cancer

Sulpiride enhances the inhibitory effect of dexamethasone on tumor growth in drug-resistant breast cancer

Female nude mice bearing MCF-7/Adr xenografts were used to investigate the anti-cancer effects of SUL and DEX. Figure $1 \mathrm{~A}$ and $1 \mathrm{~B}$, respectively, depict the tumor growth rates of various dosage regimens and images of excised tumors on d 18. The tumors appear to be resistant to epirubicin. Our observations revealed that the inhibitory effects of DEX or the combination of SUL and DEX were much greater than those of epirubicin. The final tumor volumes observed in the control, SUL $25 \mathrm{mg} / \mathrm{kg}$ and SUL $100 \mathrm{mg} / \mathrm{kg}$ groups were, respectively, $2845 \pm 454.5 \mathrm{~mm}^{3}, 3041 \pm 1390 \mathrm{~mm}^{3}$ and $2884 \pm 778.8 \mathrm{~mm}^{3}$, suggesting no significant differences among them. When DEX was administered alone at 1,2 , or $8 \mathrm{mg} \cdot \mathrm{kg}^{-1} \cdot \mathrm{d}^{-1}$, the inhibitory ratios of tumor volume compared with the control group were $51.28 \% \pm 14.99 \%, 62.44 \% \pm 5.557 \%$, and $73.42 \% \pm 10.98 \%$, respectively. In addition, when DEX was administered at $1 \mathrm{mg} \cdot \mathrm{kg}^{-1} \cdot \mathrm{d}^{-1}$ in combination with SUL at $50 \mathrm{mg} \cdot \mathrm{kg}^{-1} \cdot \mathrm{d}^{-1}$, the inhibitory ratio increased to $65.68 \% \pm 10.87 \%$, which is higher than that of DEX at $1 \mathrm{mg} \cdot \mathrm{kg}^{-1} \cdot \mathrm{d}^{-1}$ alone. Similarly, the inhibitory ratios were significantly increased to $81.48 \% \pm 5.177 \%$, $89.99 \% \pm 4.129 \%(P<0.01)$ and $88.39 \% \pm 3.456 \%(P<0.01)$ for the combination treatments of DEX at $8 \mathrm{mg} \cdot \mathrm{kg}^{-1} \cdot \mathrm{d}^{-1}$ and SUL at 25, 50 , and $100 \mathrm{mg} \cdot \mathrm{kg}^{-1} \cdot \mathrm{d}^{-1}$, respectively, indicating a more potent inhibitory effect in combination therapy than in DEX monotherapy. Moreover, the tumor burden in the SUL-treated groups was similar to that of the control group, suggesting that SUL alone could not inhibit the tumor growth in the MCF-7/Adr xenograft model. Taken together, the combina-
A

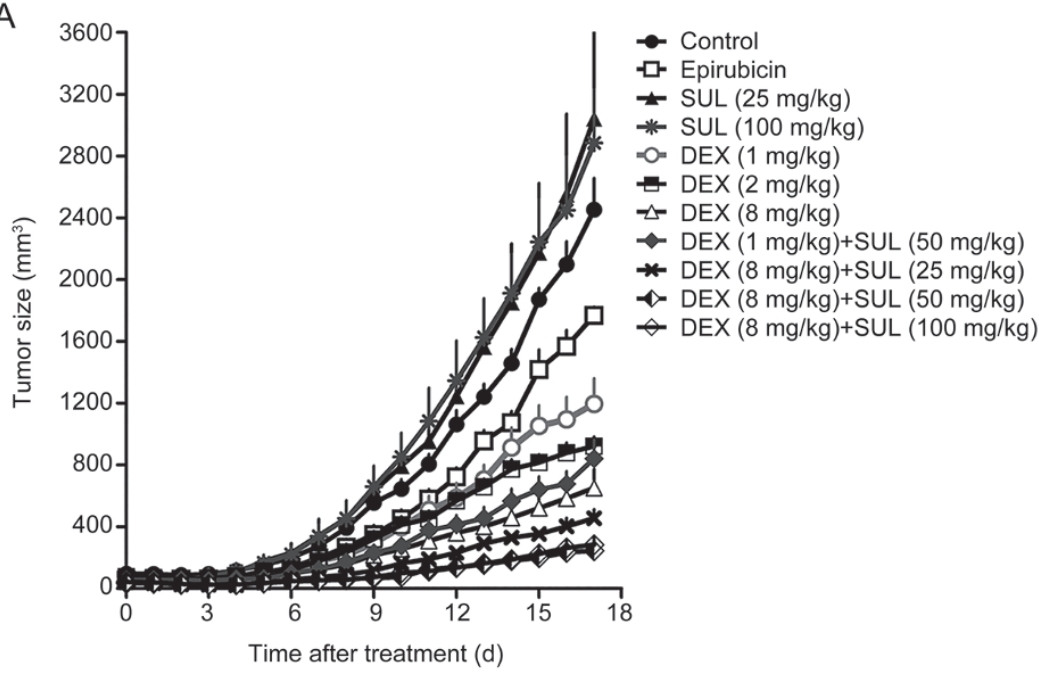

C

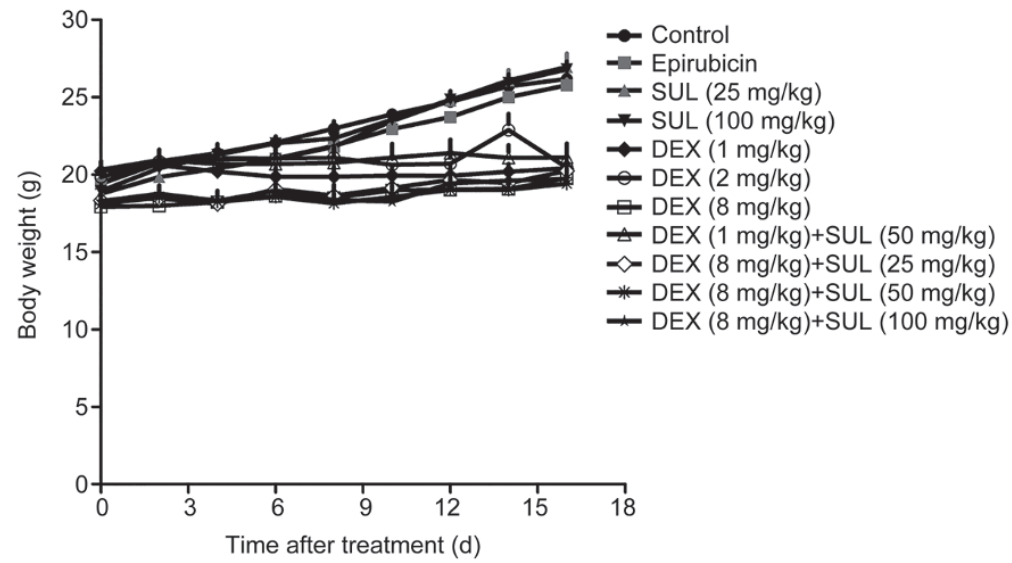

B

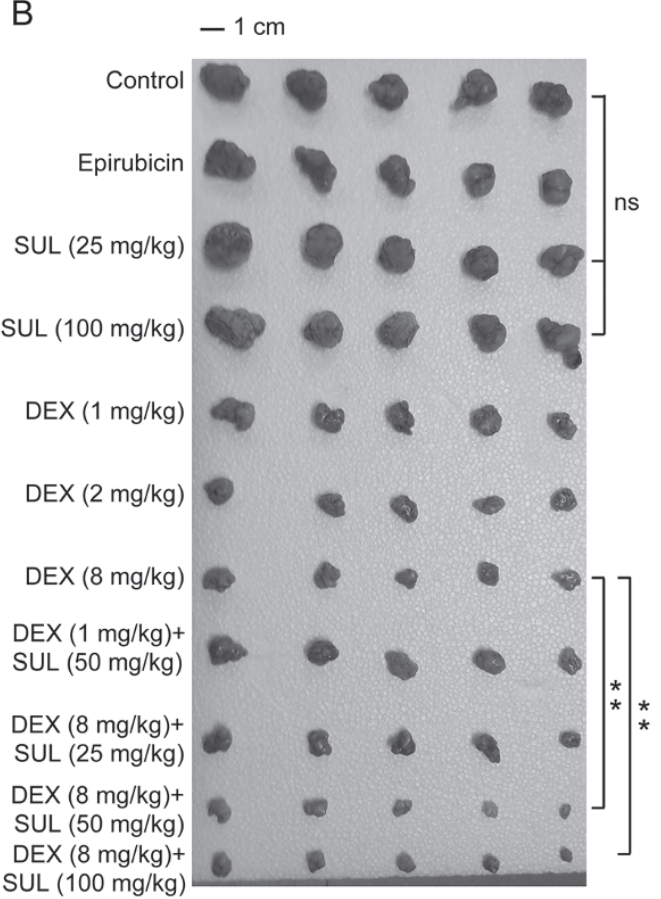

Figure 1. SUL improved the inhibitory effects of DEX on tumor growth in an MCF-7/Adr xenograft nude mice model. In the MCF-7/Adr xenograft model, mice were administered with vehicle, epirubicin (positive control), or different doses of SUL, DEX, or their combinations for $17 \mathrm{~d}$. SUL (po) and DEX (po) were administered once daily, and epirubicin (iv) was injected every three days. The tumor volumes were measured every day, and mouse weights were measured every other day. (A and B) Different doses of SUL combined with DEX significantly inhibited tumor growth. The tumor volumes in the epirubicin-treated group showed no significant difference from those of the control group. This result further confirmed the drug-resistant characteristics of MCF-7/Adr cells. (C) The mouse weights in all groups did not show evident decline, suggesting little systemic toxicity. All data are presented as the mean \pm SD $(n=5)$. SUL, sulpiride; DEX, dexamethasone; NS, non-significant; ${ }^{* *} P<0.01$. 
tion treatment groups exhibited significantly greater tumor growth inhibition compared to DEX alone.

The body weights in the combination treatment groups did not show evident decline (Figure 1C), suggesting little systemic toxicity. Moreover, no apparent toxicity to the organ tissues among different treatment groups was suggested by H\&E staining (Figure 2A). Blood tests of the MCF-7/ Adr xenograft mice revealed little evident hematotoxicity after the combination treatment of SUL and DEX with the exception of elevated white blood cell counts, which is a common side effect of $\mathrm{DEX}^{[23]}$ (Figure 2B).

The enhancement of DEX anti-cancer activity by sulpiride was reversed by 7-OH-DPAT in drug-resistant breast cancer in vitro and in vivo

To investigate the mechanisms of SUL activity, 7-OH-DPAT, a specific D2DR agonist, was introduced to in vitro colony formation assays with MCF-7/Adr cells and in vivo tumor growth kinetics studies with MCF-7/Adr xenografts. As shown in Figure 3A and 3B, MCF-7/ Adr cells treated with SUL or 7-OH-DPAT alone showed no effect on colony formation, whereas exposure to DEX reduced colony formation compared with the control group. The combination of SUL and DEX obviously enhanced this colony formation inhibition. The number of colonies formed in the SUL+DEX+7-OH-DPAT group was similar to that in the DEX group, indicating that the effects of SUL were reversed by 7-OH-DPAT.

To clarify the function of SUL in vivo, 7-OH-DPAT was administered intratumorally concurrently with both SUL and DEX in MCF-7/Adr xenografts. The tumor growth rate in the 7-OH-DPAT-treated group was similar to that of the control group (Figure 3C and 3D), suggesting no inhibitory or stimulatory effect of 7-OH-DPAT on tumor growth. The tumor volumes observed on d 18 were $651.8 \pm 269.2 \mathrm{~mm}^{3}$ for the DEXtreated group and $705.2 \pm 254.9 \mathrm{~mm}^{3}$ for the SUL+DEX+7-OHDPAT group, indicating no significant difference between these two groups; however, the volume of the SUL+DEX group was $284.5 \pm 84.71 \mathrm{~mm}^{3}$. These results indicated that
A
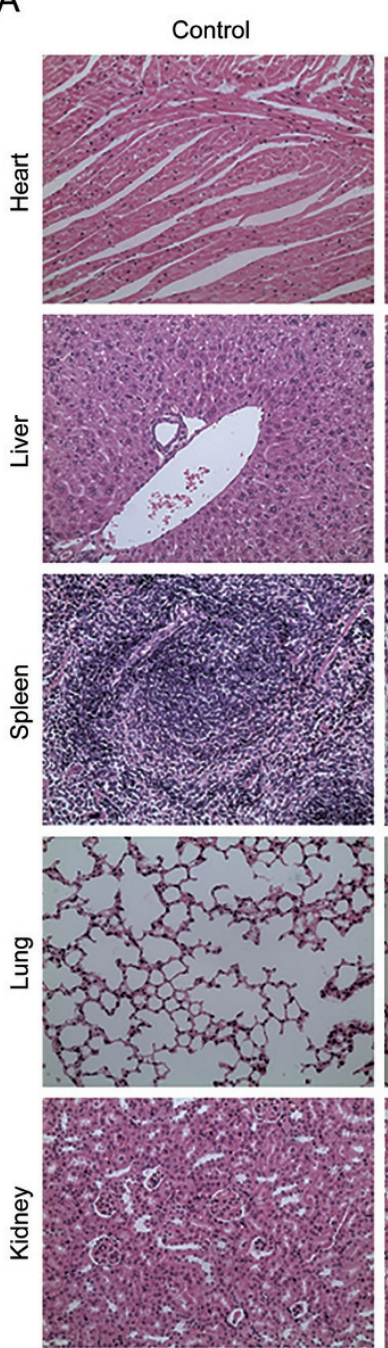

DEX: $8 \mathrm{mg} / \mathrm{kg}$
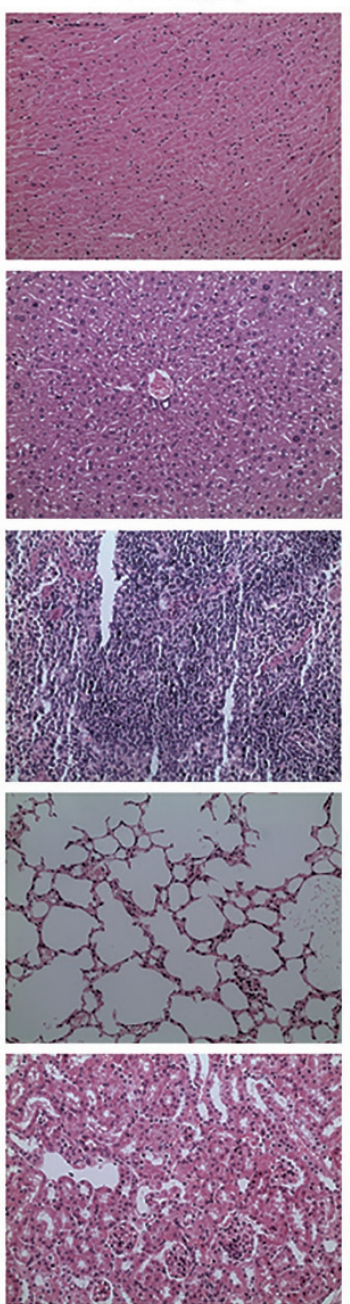

SUL: $100 \mathrm{mg} / \mathrm{kg}$
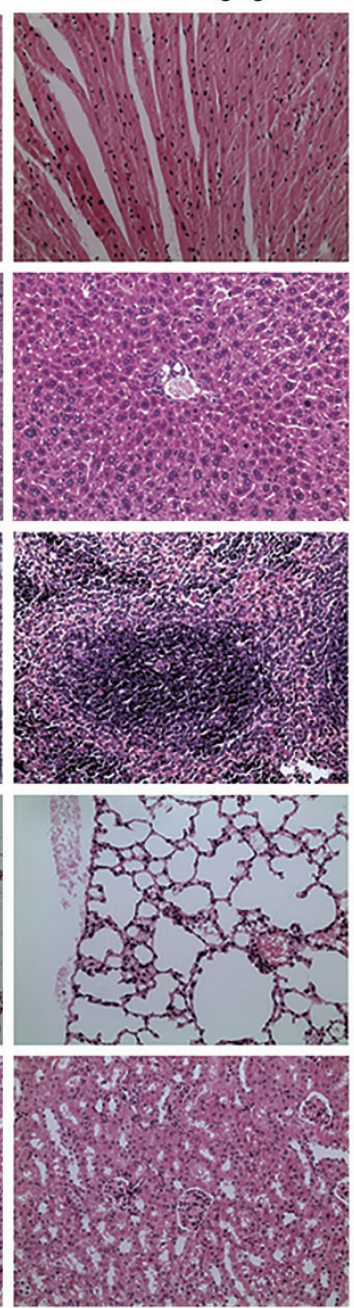

SUL: $50 \mathrm{mg} / \mathrm{kg}$
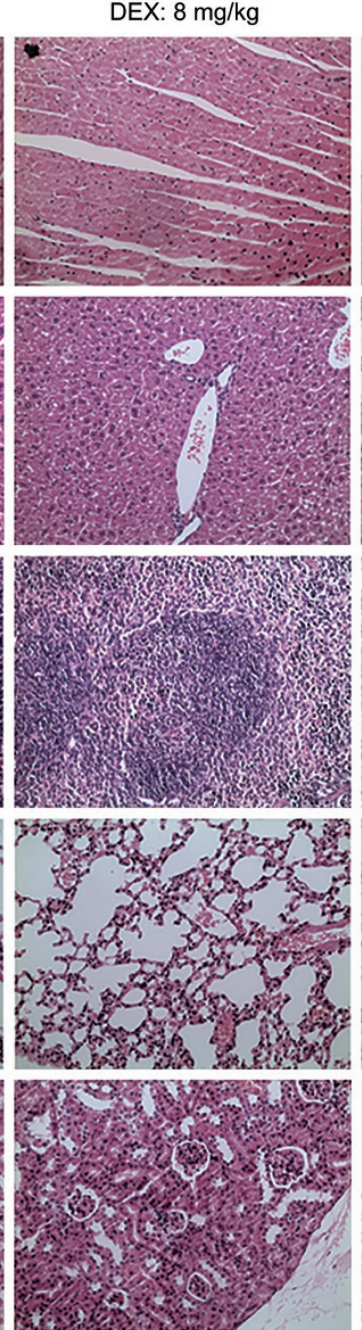

SUL: $100 \mathrm{mg} / \mathrm{kg}$ DEX: $8 \mathrm{mg} / \mathrm{kg}$
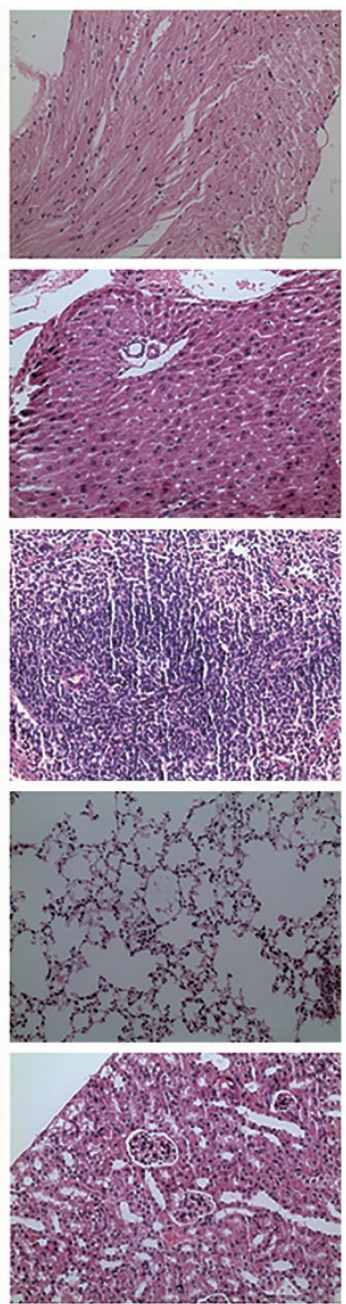

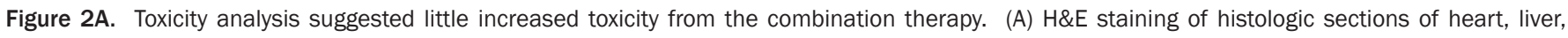
spleen, lung, and kidney from different treatment groups of MCF-7/Adr xenograft nude mice. The images are magnified 20×. 
B
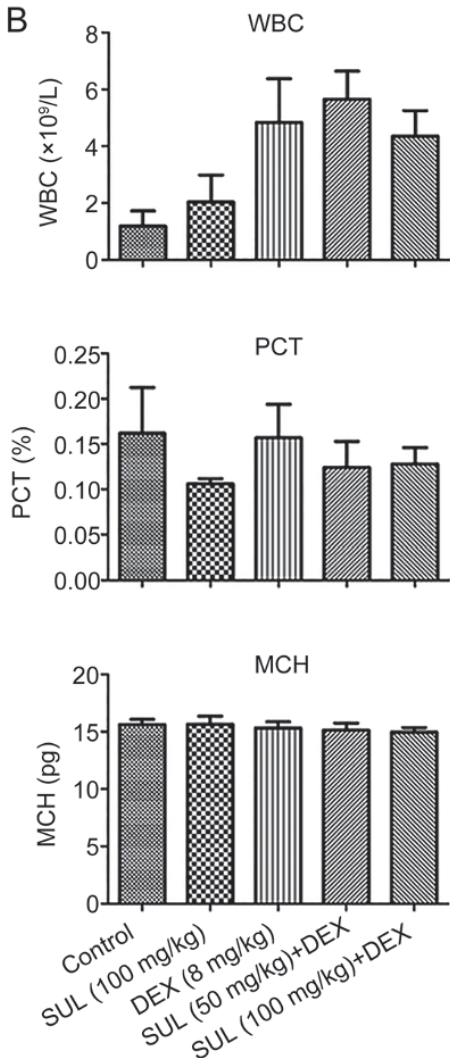
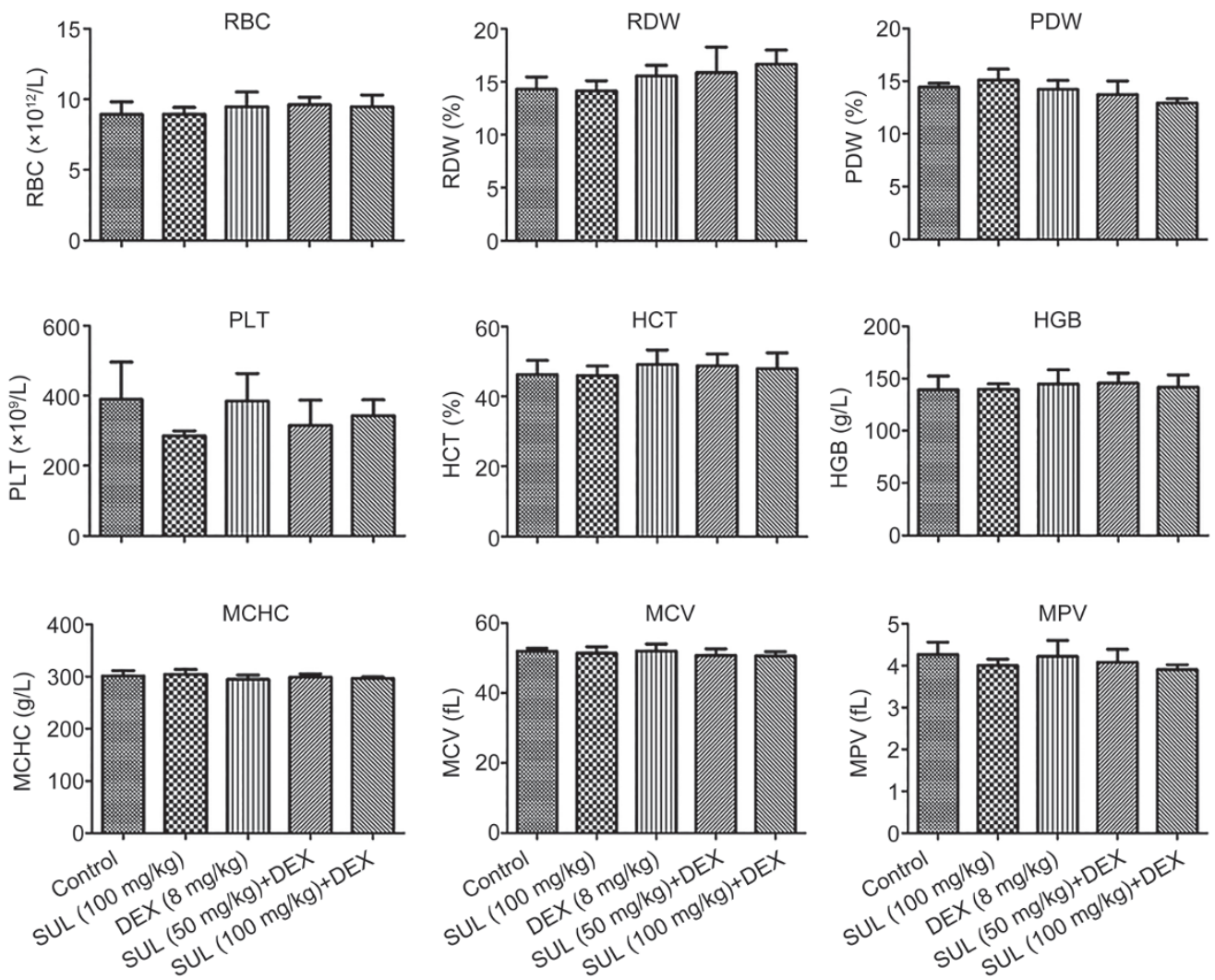

Figure 2B. Toxicity analyses suggested little increased toxicity from the combination therapy. (B) Hemogram analyses of blood samples on the 18th $d$ after treatment with SUL, DEX or their combinations in MCF-7/Adr tumor-bearing nude mice. No evident hematotoxicity was seen after the combination treatment of SUL and DEX except an increased white blood cell count. WBC, white blood count; RBC, red blood count; RDW, red cell distribution width; PDW, platelet distribution width; PCT, thrombocytocrit; PLT, platelet count; HCT, hematocrit; HGB, hemoglobin; MCH, mean corpuscular hemoglobin; MCHC, mean corpuscular hemoglobin concentration; MCV, mean corpuscular volume; MPV, mean platelet volume; SUL, sulpiride; DEX, dexamethasone.

7-OH-DPAT completely reversed the enhanced effects of SUL on DEX treatment, rendering the treatment equivalent to that of DEX alone.

\section{Sulpiride reduced the proportion of cancer stem-like cells in vitro and in vivo}

To further investigate the mechanism of SUL, the proportion of CSCs was assessed in vitro and in vivo. For the in vitro study, MCF-7/Adr cells were cultured in the presence of SUL at various concentrations followed by phenotype analysis on a flow cytometer. CSCs accounted for $13.0 \% \pm 4.59 \%$ of cells in the control group, and this quantity decreased to $8.21 \% \pm 3.53 \%$ (20 $\mathrm{\mu mol} / \mathrm{L}), 7.11 \% \pm 3.74 \%(40 \mu \mathrm{mol} / \mathrm{L})$, and $4.12 \% \pm 2.46 \%$ $(50 \mu \mathrm{mol} / \mathrm{L}$ ) in the SUL-treated groups (Figure $4 \mathrm{~A}$ and $4 \mathrm{C}$ ), indicating that SUL reduces the proportion of CSCs in a dosedependent manner.

We also investigated changes to the CSC population after different treatments in MCF-7/Adr xenografts. As shown in Figure $4 \mathrm{~B}$ and $4 \mathrm{D}$, the CSC population was decreased from $9.39 \% \pm 1.55 \%$ (vehicle) to $6.42 \% \pm 4.65 \%\left(25 \mathrm{mg} \cdot \mathrm{kg}^{-1} \cdot \mathrm{d}^{-1}\right)$ and $3.88 \% \pm 1.50 \%\left(100 \mathrm{mg} \cdot \mathrm{kg}^{-1} \cdot \mathrm{d}^{-1}\right)$ by SUL treatment. However, the population increased to $12.88 \% \pm 2.04 \%$ in the DEX-treated group. When SUL was treated concurrently with DEX, the population of CSCs significantly declined from $12.88 \% \pm 2.04 \%$ to $8.15 \% \pm 1.66 \%(P<0.05)$. Interestingly, $7-\mathrm{OH}-\mathrm{DPAT}$ monotherapy demonstrated a higher level of CSCs than the control group; moreover, the effect of combination SUL and DEX was reversed to nearly the same level as that of DEX monotherapy when 7-OH-DPAT was added. These observations indicated that SUL depletes CSCs by functioning on the D2DR.

The anti-cancer effects of the combination therapy on metastatic breast cancer

Sulpiride enhanced the inhibition of lung metastasis by dexamethasone in a 4T1 xenograft model

To assess whether the combination therapy of SUL and DEX inhibited tumor metastasis, a 4T1 xenograft model was used. After 2 weeks of treatment, the animals were euthanized, and their lungs were harvested to assess lung metastasis. Figure 5 shows the images of lungs and the representative histological sections from different treatment groups. Large 4T1 tumor metastatic nodules were found in the control and SUL-treated groups, whereas the tumor area and nodules were decreased in the DEX-treated group and the combination treatment group. Of the four treatment groups, the combination of SUL and DEX showed the greatest inhibition of lung metastasis. 

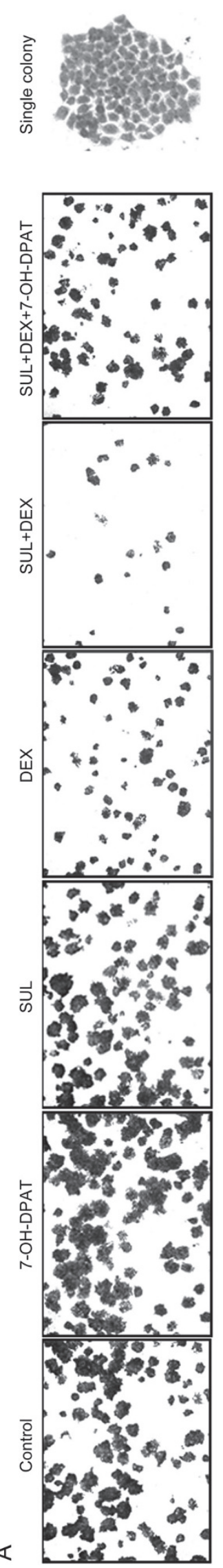
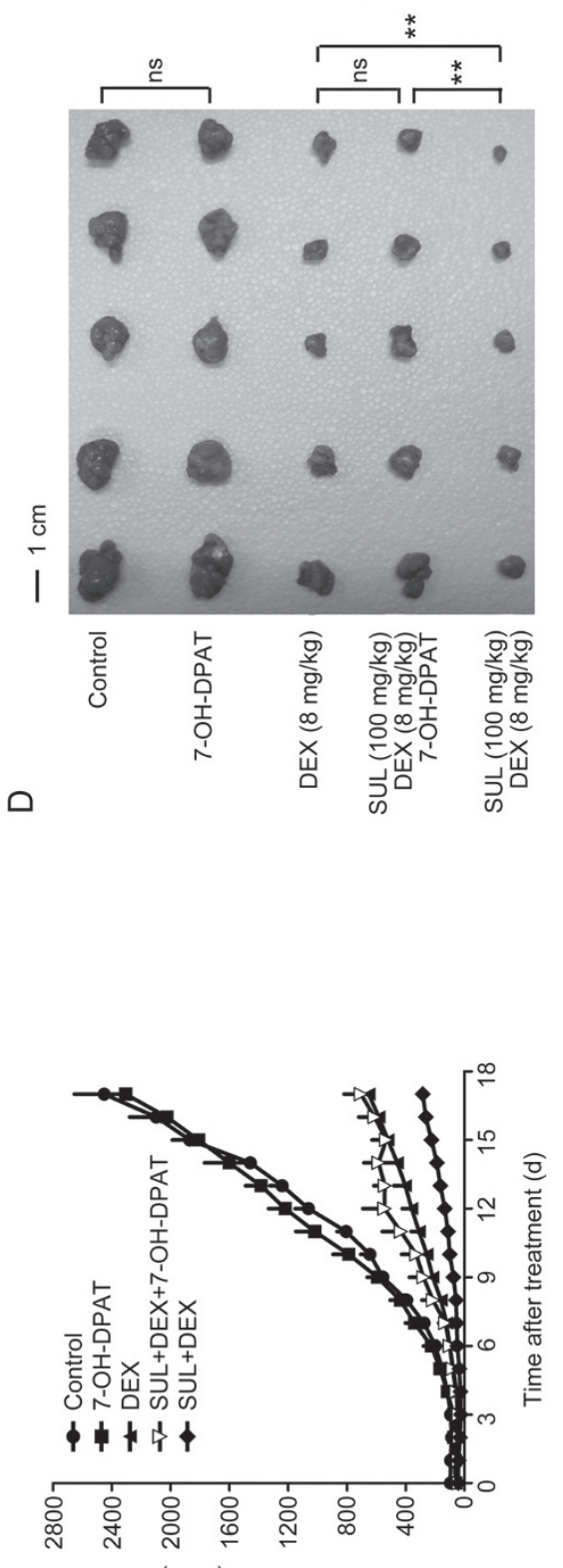

U

( $\left.{ }_{\varepsilon} w u\right)$ əz!̣s $\lrcorner o u n \perp$

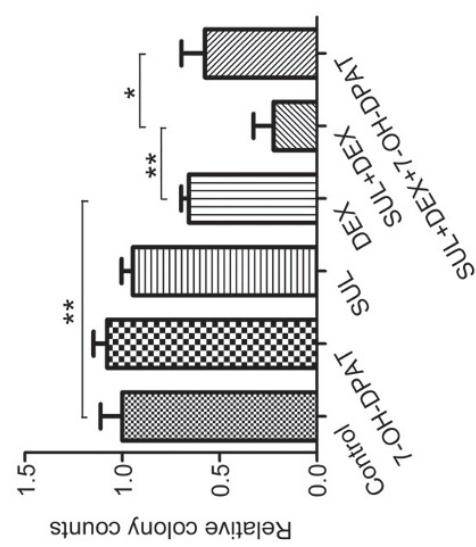

$\infty$

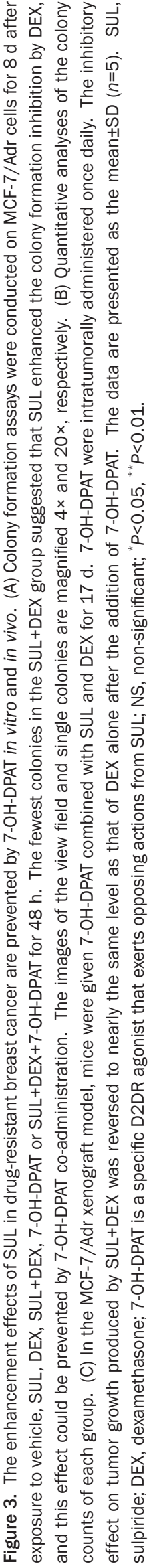




\section{A}

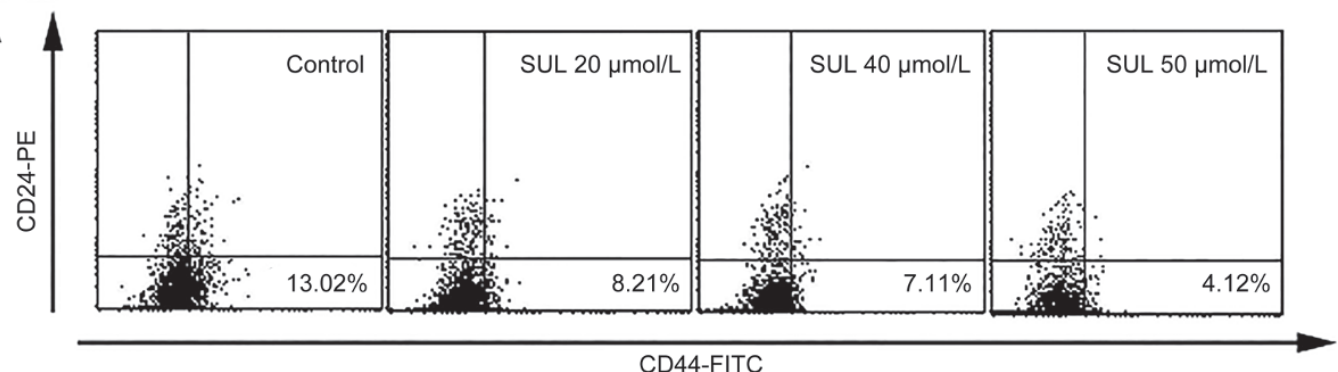

B

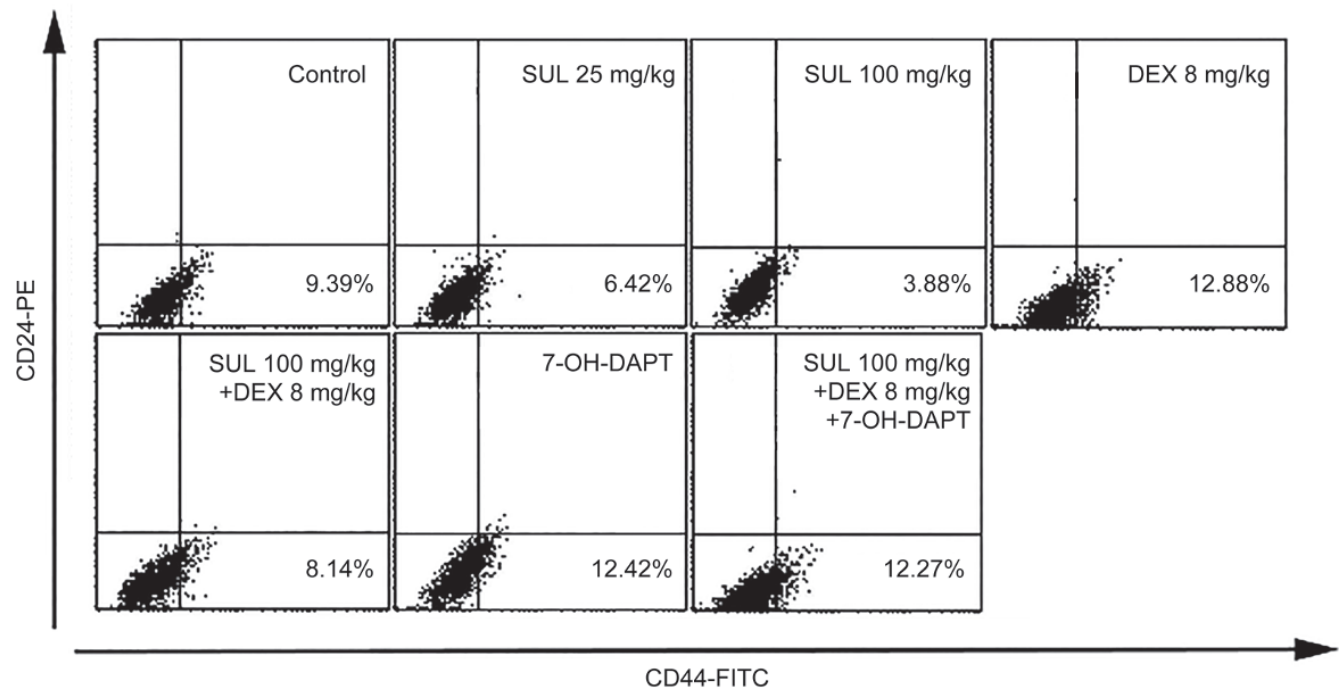

C

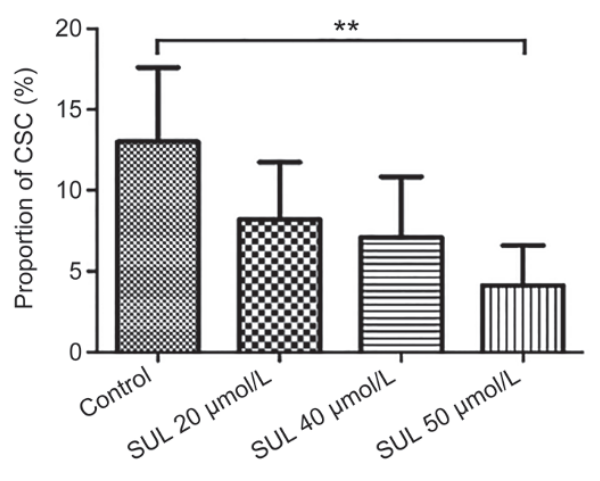

D

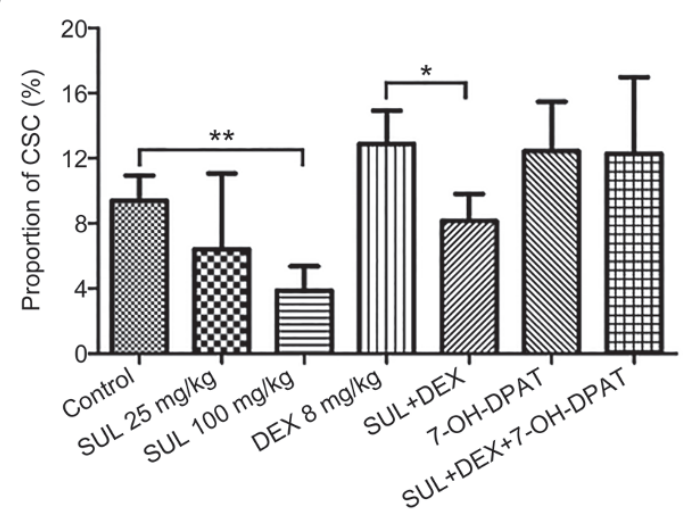

Figure 4. SUL reduced the proportion of CSCs in vitro (A and $C$ ) and in vivo (B and D). In the in vitro analysis, MCF-7/Adr cells were cultured in the presence of DMSO (1\%) and different concentrations of SUL $(20,40,50 \mu \mathrm{mol} / \mathrm{L})$ for $48 \mathrm{~h}$ before staining with anti-CD44-FITC and anti-CD24-PE. CSCs, defined as $\mathrm{CD}_{4} 4^{+} / \mathrm{CD} 24^{-}$cells, were measured on a FACScan flow cytometer. (A) Representative flow cytometer analysis of the SUL-induced reduction of CSC frequency. (C) SUL significantly reduced the proportion of CSCs in a dose-dependent manner. In the in vivo analyses, tumor tissues from different treatment groups were minced, digested and incubated at $37^{\circ} \mathrm{C}$ for $4-6 \mathrm{~h}$ before staining with anti-CD44-FITC and anti-CD24-PE. CSCs (CD44 ${ }^{+} / \mathrm{CD}^{-} 4^{-}$ cells) were analyzed on a FACScan flow cytometer. (B) Representative flow cytometer analysis of the changes of CSC frequency. (D) The CSC proportion was remarkably reduced in the SUL monotherapy group, but it increased in the DEX monotherapy group. When DEX was administered in combination with SUL, the proportion of CSCs was significantly reduced, and this effect could be reversed by $7-\mathrm{OH}-\mathrm{DPAT}$. All data are presented as the mean \pm SD ( $n=4$ ). SUL, sulpiride; DEX, dexamethasone; ${ }^{*} P<0.05,{ }^{* *} P<0.01$.

\section{Sulpiride enhanced the effect of dexamethasone on the expres-} sion of metastasis-associated biomarkers

To investigate the expression of metastasis-associated biomarkers, motility- and epithelial-mesenchymal transition
(EMT)-related proteins in tumor tissues, including E-cadherin, $\mathrm{N}$-cadherin, claudin1, matrix metalloproteinase MMP-2, and MMP-9, were measured using ELISA kits. As shown in Figure $6 \mathrm{~A}$, the expression of MMP-2, MMP-9, and N-cadherin were 
A
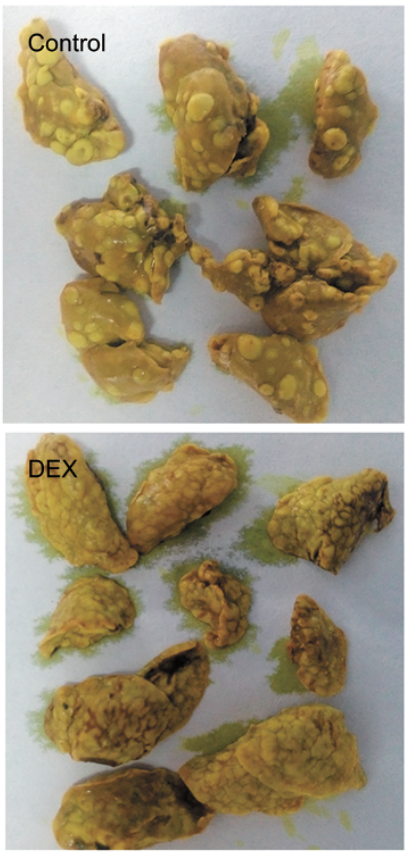

B
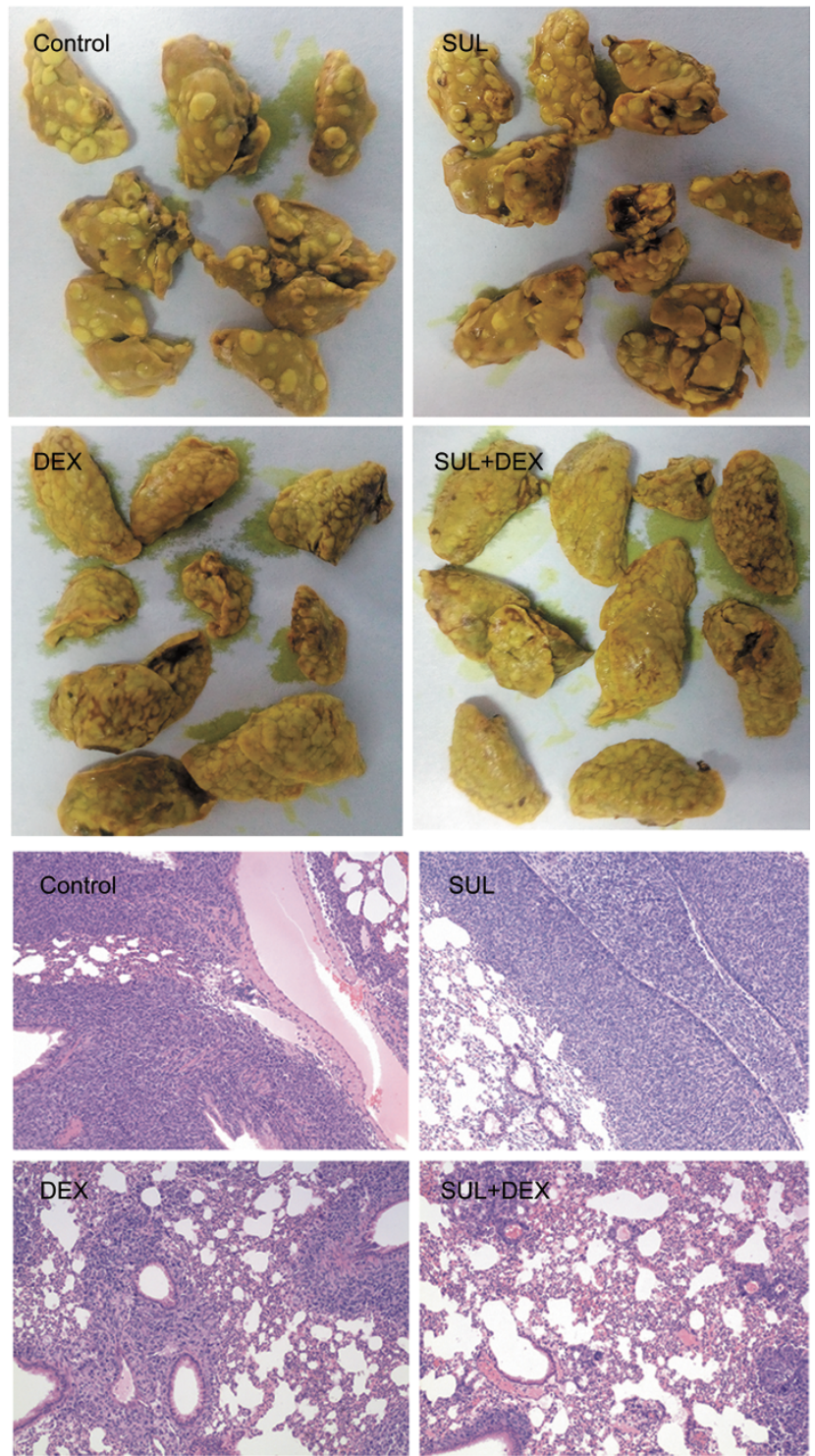

C

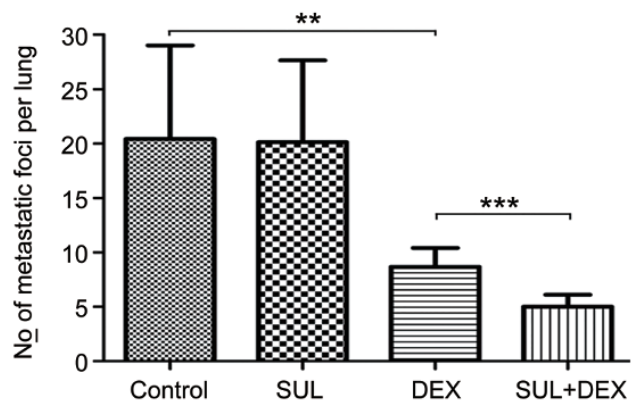

Figure 5. SUL enhanced the inhibitory effect of dexamethasone on lung metastasis in a 4T1 xenograft model. 4T1 orthotopic xenograft mice were administered with vehicle, SUL $\left(50 \mathrm{mg} \cdot \mathrm{kg}^{-1} \cdot \mathrm{d}^{-1}\right)$, DEX $\left(8 \mathrm{mg} \cdot \mathrm{kg}^{-1} \cdot \mathrm{d}^{-1}\right)$ or SUL+DEX (50 and $8 \mathrm{mg} \cdot \mathrm{kg}^{-1} \cdot \mathrm{d}^{-1}$ ) for 2 weeks before being euthanized and undergoing metastasis-related analysis. The harvested lungs were stained with Bouin's Fluid, embedded in paraffin wax, sliced, mounted on slides, and stained with $H \& E$. Images of lungs $(A)$, representative images of $H \& E$ staining of the harvested lungs $(B)$, and corresponding quantification of metastatic foci (C). SUL, sulpiride; DEX, dexamethasone. ${ }^{* *} P<0.01,{ }^{* * *} P<0.001$. significantly decreased $(P<0.05)$ after treatment with DEX alone, and the expression of MMP-2 was further decreased $(P<0.001)$ when SUL was added. No significant difference was observed among control, SUL, and DEX-treated groups for the expression of E-cadherin; it was significantly increased $(P<0.01)$ after treatment with DEX combined with SUL. Our results showed that among these biomarkers, MMP-2 and E-cadherin were sensitive to the combination treatment of SUL and DEX, indicating that these two proteins might be involved in the metastasis inhibition by this combined therapy and that SUL enhanced the effect of DEX on these metastasis-related biomarkers.

Sulpiride enhanced the inhibitory effect of dexamethasone on the colony formation of metastatic tumor cells by antagonizing D2DR

4T1 and MDA-MB-231 cells were used for colony formation assays under different drug treatment conditions. Tumor cells treated with SUL or 7-OH-DPAT alone showed no effect on colony formation, and single exposure to DEX reduced colony counts compared with the control group (Figure 6B and $6 \mathrm{C}$ ). However, the combination of SUL and DEX obviously enhanced colony formation inhibition, and the colony formation in the SUL+DEX+7-OH-DPAT group was similar to that of the DEX group, indicating that the effect of SUL was reversed by $7-\mathrm{OH}-\mathrm{DPAT}$. These observations showed that SUL might enhance the inhibitory effect of DEX on metastatic tumor cell colony formation by antagonizing D2DR.

\section{Sulpiride enhanced the inhibitory effects of dexamethasone on the migration and invasion of metastatic tumor cells by antagonizing $D 2 D R$}

The capacity for tumor cell motility plays an important role during tumor progression and metastasis. To investigate whether the combination of SUL and DEX would have a better inhibitory effect on tumor cell migration and invasion, and to study the underlying mechanisms, 4T1 and MDA-MB-231 cells were subjected to wound healing, Transwell migration, and invasion assays in the presence of vehicle (Control), SUL, DEX, SUL+DEX, 7-OH-DPAT, and SUL+DEX+7-OH-DPAT.

As shown in Figure 7A and 7D, the wound area in the groups cultured with SUL alone showed no significant difference from the control group, whereas the wound area in the DEX-treated group was slightly larger. However, a greatly increased wound area was observed in the SUL+DEX group. The ability of SUL to enhance the effect of DEX was reversed by 7-OH-DPAT.

Similarly, treatment with DEX alone had some ability to inhibit cell migration and invasion in the Transwell assays (Figure 7B-7D). No significant difference was observed in the SUL or 7-OH-DPAT groups relative to the control group. However, a greater increase of the inhibitory effect was observed in the SUL+DEX groups. The numbers of migrated and invaded cells in the SUL+DEX+7-OH-DPAT groups were similar to those of DEX-treated groups, suggesting that the effect of SUL in these groups was reversed by 7-OH-DPAT 


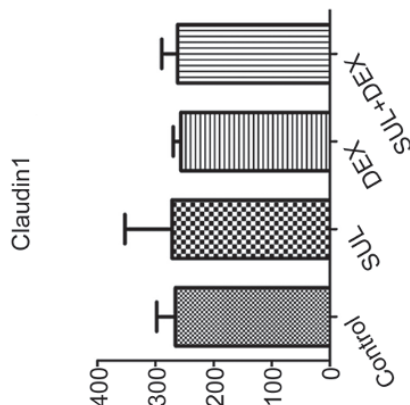

(ךm/6d) uọ̣exұuəsuоว

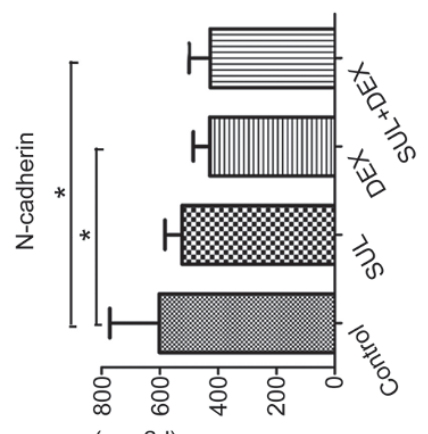

(ךm/6d) uo!̣eגиuәэuо
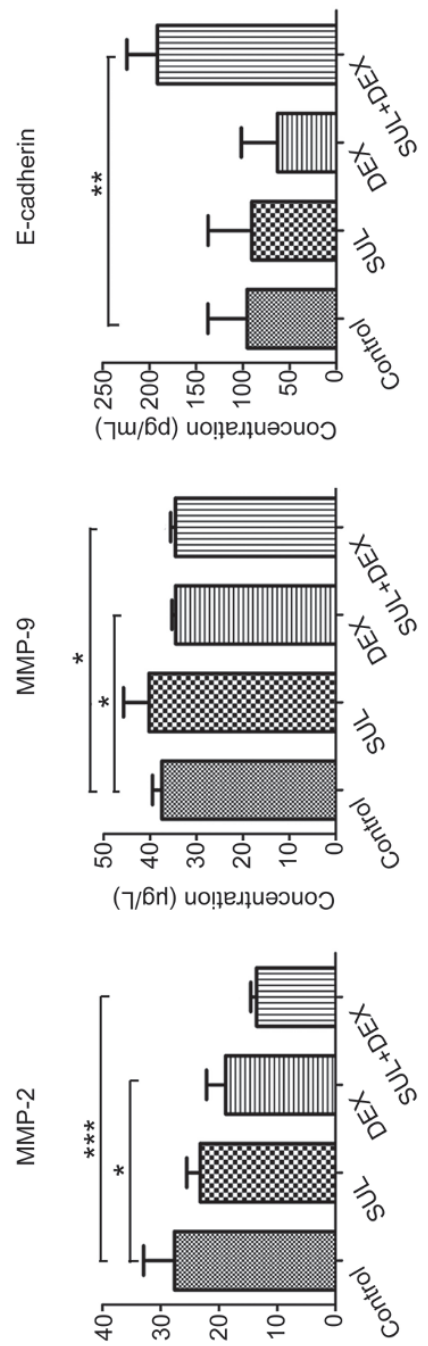

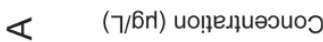
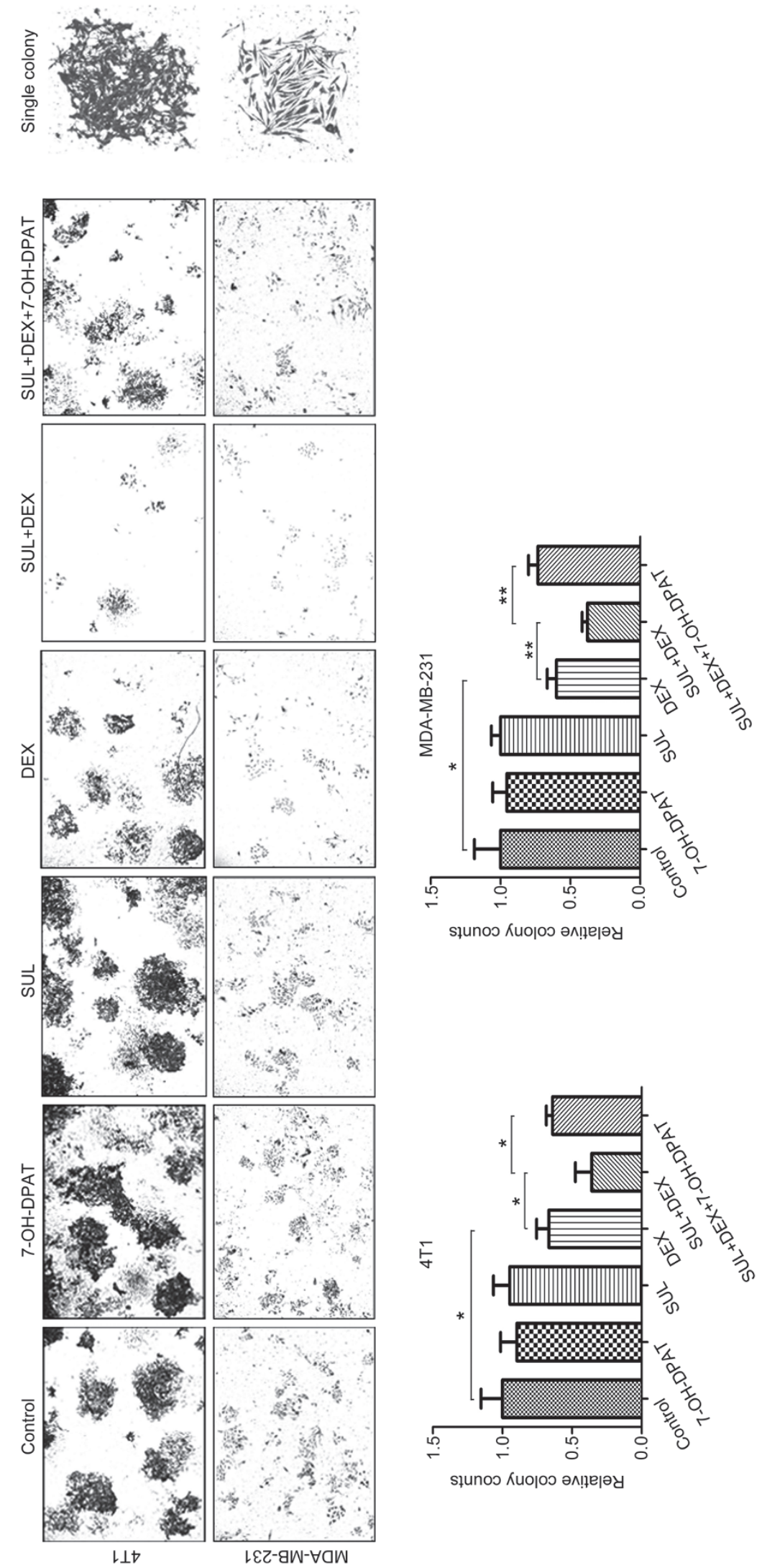

$\infty$
다에

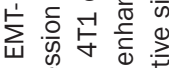

흔 흥

व

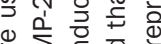

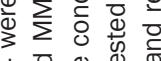

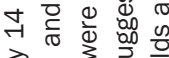

ते 完

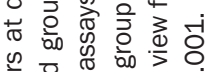

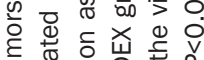

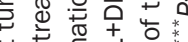

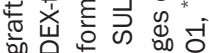

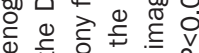

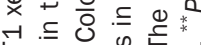

守

茙

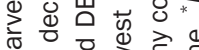

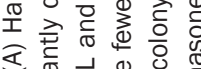

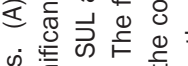

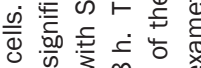

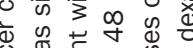

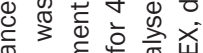

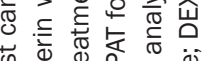

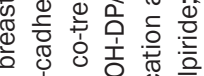

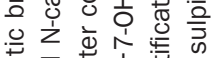

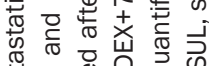

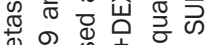

E

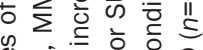

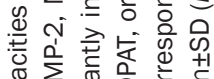

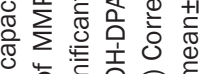

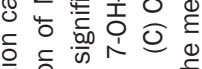

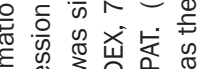

है

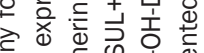

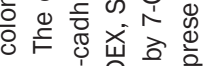

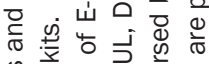

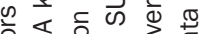

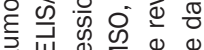

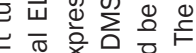

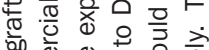

कू एँ

选 ह

당 ठ ठ

$\simeq \frac{\pi}{5}$ 元

क ज

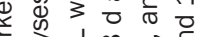

产 㐫

흥 त

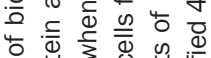

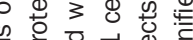

\% 흐ㅇㅝㅔ

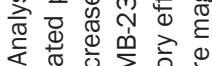

0 인

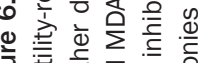

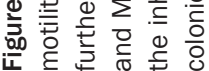


A
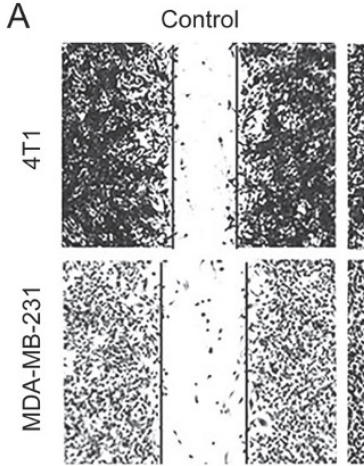

7-OH-DPAT

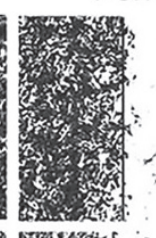

SUL
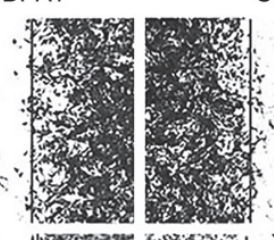
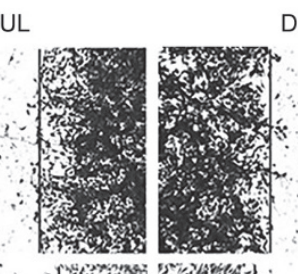

DEX

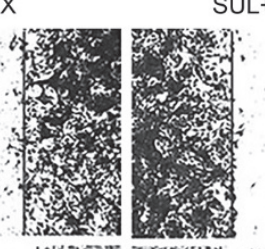

SUL+DEX
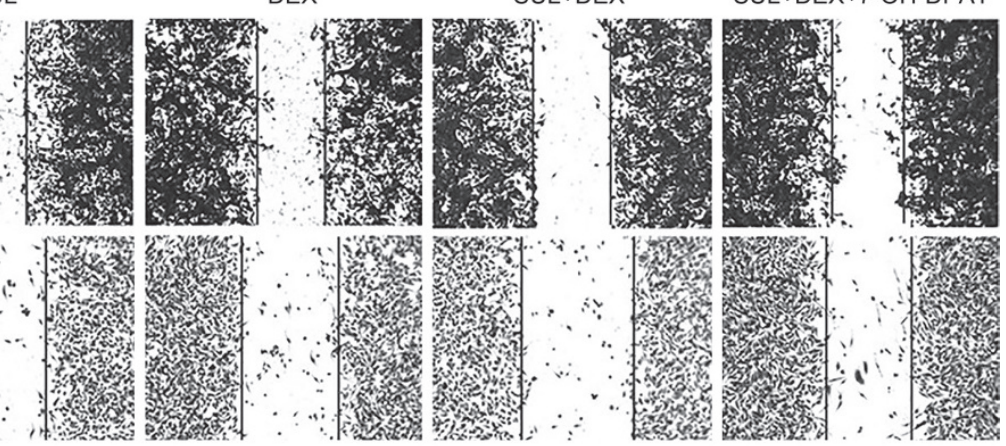

B
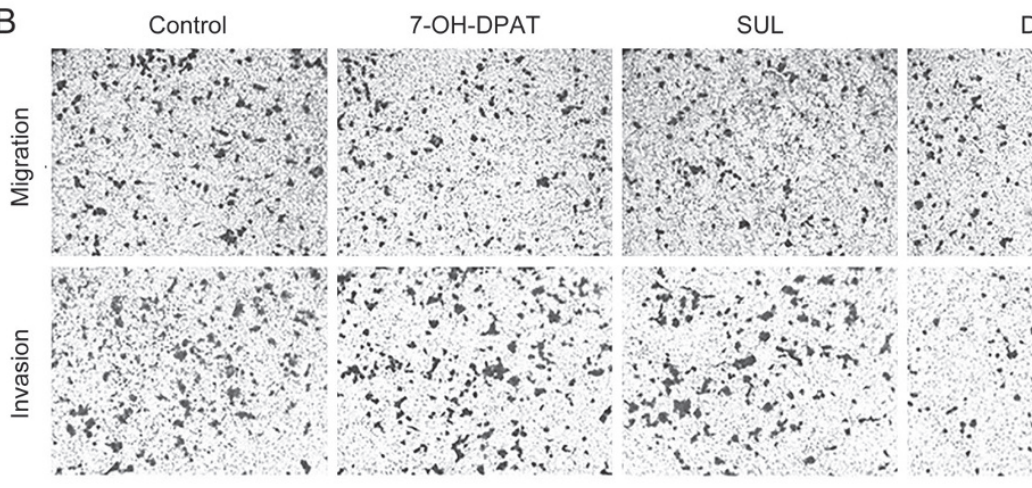

DEX

SUL+DEX

SUL+DEX+7-OH-DPAT

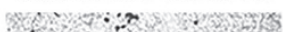

C
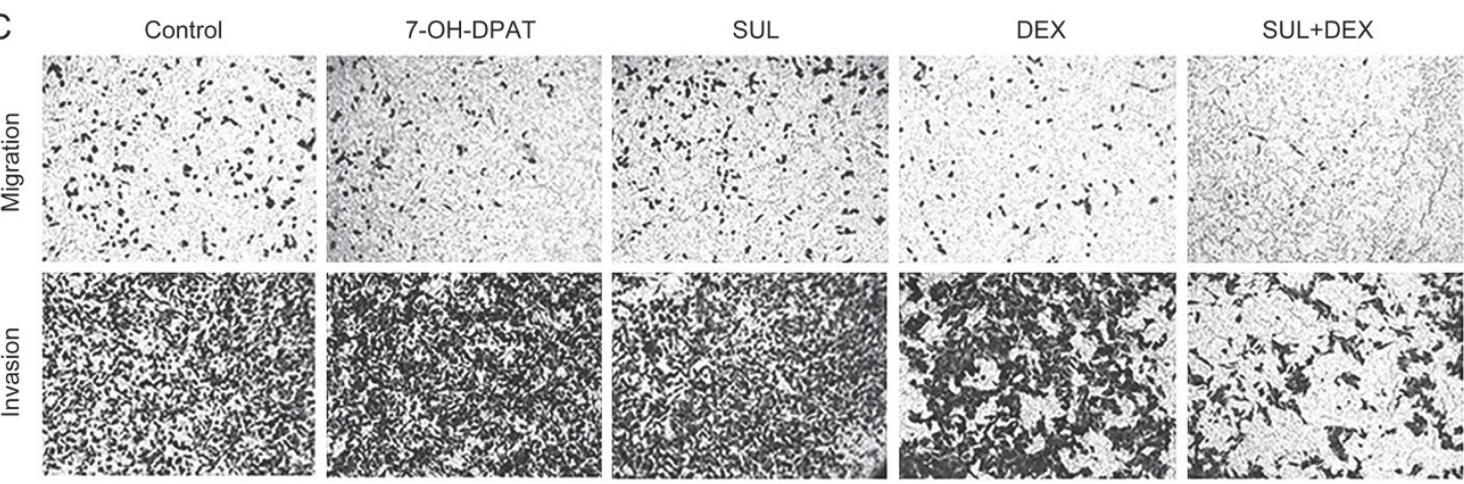

SUL+DEX+7-OH-DPAT

Figure 7A-7C. SUL enhanced the inhibitory effects of DEX on the migration and invasion of metastatic tumor cells by antagonizing D2DR. Wound healing assays (A) on 4T1 cells and MDA-MB-231 cells after exposure to DMSO, SUL, DEX, SUL+DEX, 7-OH-DPAT, or SUL+DEX+7-OH-DPAT for 8-12 h. Transwell migration and invasion assays on 4T1 cells (B) and MDA-MB-231 cells (C) after treatment with DMSO, SUL, DEX, SUL+DEX, 7-OH-DPAT, or SUL+DEX+7-OH-DPAT for 12-16 h.

and further demonstrating that the potentiating effects of SUL depend on the antagonism of D2DR.

\section{Discussion}

D2DR antagonists have been used as adjuvants of chemotherapy drugs for cancer therapy ${ }^{[12]}$, and the anti-cancer effects of DEX for drug-resistant and metastatic cancer has been documented several times ${ }^{[6,7,9-11]}$. Moreover, in our previous studies $^{[6,7]}$, DEX exerted a better anti-cancer effect than traditional chemotherapeutics such as gemcitabine and tamoxifen, and the effect might be further improved when combined with other agents ${ }^{[7]}$. These prior studies prompted us to investigate the anti-cancer effects of DEX in combination with SUL as well as the underlying mechanisms in drug-resistant and metastatic breast cancer. In this study, we demonstrated that SUL remarkably enhanced the anti-cancer activity of DEX by antagonizing D2DR, and no evident increased toxicity was observed in the combination therapy.

We selected MCF-7/Adr cells as drug-resistant cells in vitro and in vivo. To confirm the drug resistance of this cell line, we conducted sulforhodamine B (SRB) colorimetric assays to assess the cytotoxicity of adriamycin in MCF-7 parental cells and MCF-7/Adr cells, and the $\mathrm{IC}_{50}$ values of adriamycin in the two cell lines were $0.44 \mu \mathrm{mol} / \mathrm{L}$ and approximately 50 $\mu \mathrm{mol} / \mathrm{L}$, respectively. Moreover, colony formation was much higher for MCF-7/Adr cells than for MCF-7 cells with the same numbers of seeded cells and under the same treatment conditions of both DEX mono-therapy and DEX/SUL combi- 

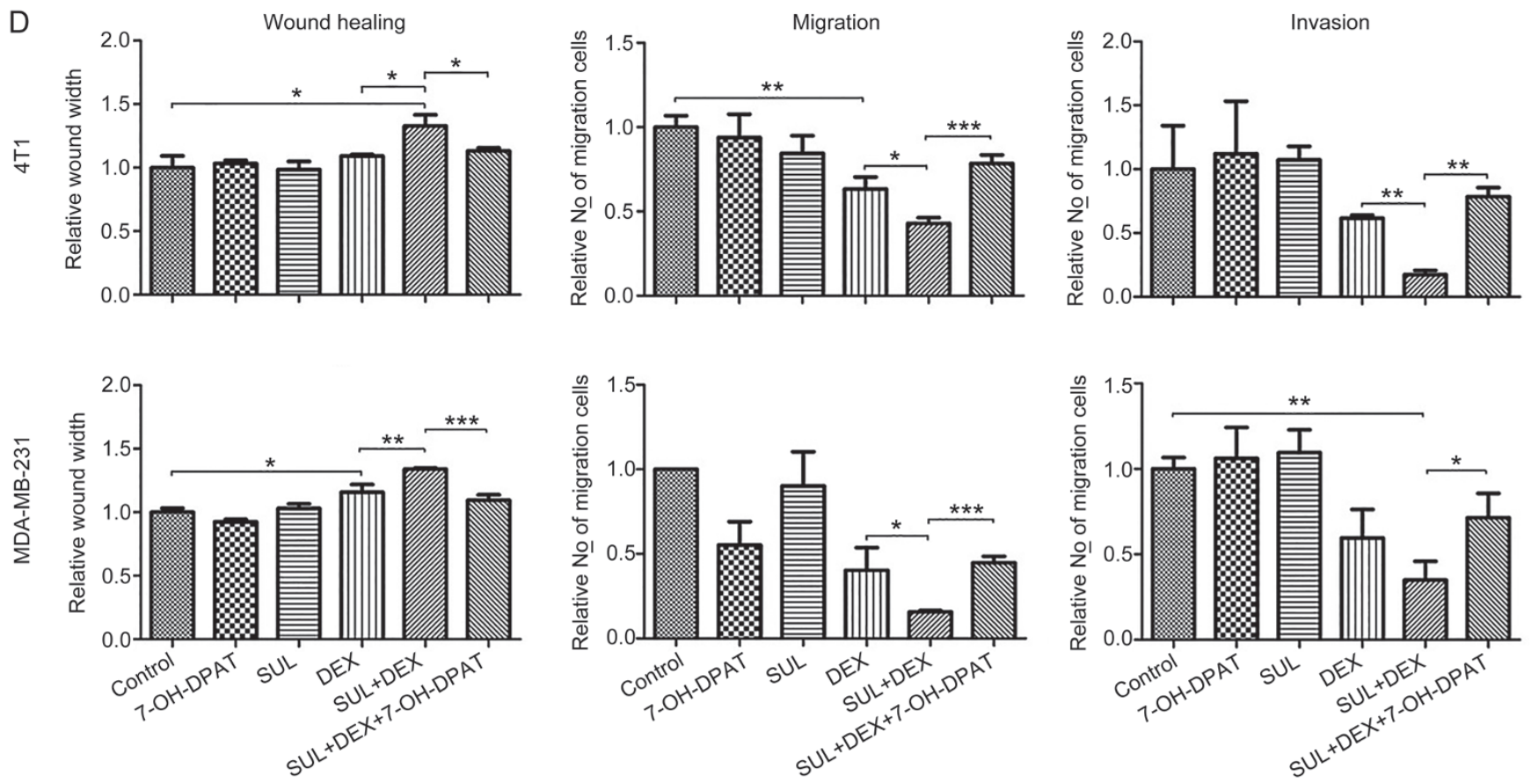

Figure 7D. SUL enhanced the inhibitory effects of DEX on the migration and invasion of metastatic tumor cells by antagonizing D2DR. (D) Corresponding quantification analyses of the wound width, migration, and invasion of cells. The widest wound space and the fewest migrated cells on the lower surface of the membrane after the combined treatment of SUL and DEX suggested the most powerful inhibitory effect on tumor cells migration and invasion. These inhibitory effects were restored to nearly the same levels as with DEX alone after the addition of 7-OH-DPAT. SUL, sulpiride; DEX, dexamethasone. ${ }^{*} P<0.05,{ }^{* *} P<0.01,{ }^{* * *} P<0.001$.

nation therapy (Supplementary Figure S1). Moreover, in the MCF-7/Adr xenograft model, epirubicin showed no inhibitory effect on tumor growth; the tumor volumes in the epirubicintreated group and the control group were nearly the same (Figure 1A and 1B). All these results indicate that the MCF-7/ Adr cell line used in this study is drug resistant and is suitable for our pharmacodynamic and mechanistic investigation.

We investigated the growth kinetics of tumors under various treatments. The tumor growth was remarkably suppressed by the DEX monotherapy at 1 or $2 \mathrm{mg} \cdot \mathrm{kg}^{-1} \cdot \mathrm{d}^{-1}$. The difference of the tumor volumes between the DEX $8 \mathrm{mg} \cdot \mathrm{kg}^{-1} \cdot \mathrm{d}^{-1}$ group and the $2 \mathrm{mg} \cdot \mathrm{kg}^{-1} \cdot \mathrm{d}^{-1}$ group was not statistically significant, which may due to the reduction of DEX concentration caused by the auto-induction of a DEX-metabolizing enzyme at high dose ${ }^{[24]}$. Moreover, SUL significantly enhanced the inhibitory effect of DEX on tumor growth, and no evident increased toxicity was observed with the combination therapy, suggesting that the combination of SUL and DEX may be an applicable therapy for drug-resistant breast cancer.

Colony formation assays are usually used to evaluate the tumorigenic capacity of tumor cells ${ }^{[25,26]}$. In this study, the colony formation of MCF-7/Adr, 4T1, and MDA-MB-231 cells was remarkably suppressed by the combination treatment of SUL and DEX, suggesting that SUL may enhance the inhibitory effect of DEX on tumorigenesis. In addition, colony formation assays were used to test the effects of SUL and DEX on MCF-7 parental cells, and the trend of effects with MCF-7 parental cells was similar to that with MCF-7/Adr cells (Supplementary Figure S1), indicating that the co-treatment of SUL and DEX is effective in both drug-resistant and drug-sensitive cancer cells.

4T1 and MDA-MB-231 cell lines are commonly used as metastatic breast cancer cells ${ }^{[27,28]}$. In our study, the wound healing assays, Transwell migration, and invasion assays were conducted on 4T1 and MDA-MB-231 cells, and 4T1 xenograft nude mice were also used to assess the anti-cancer effects of DEX combined with SUL in metastatic breast cancer. As expected, migration and invasion capacities and lung metastasis were remarkably suppressed in the SUL+DEX treated groups, and the suppression was clearly improved compared to DEX alone. These results revealed that SUL can enhance the anti-cancer effects of DEX in metastatic breast cancer.

EMT is usually activated during cancer metastasis ${ }^{[2,30]}$. In addition, the MMPs, which mediate extracellular proteolysis, form the most prominent family of proteinases associated with tumorigenesis and metastasis ${ }^{[29,31]}$. The expression of MMPs and N-cadherin in tumors can promote tumor metastasis through the mediation of extracellular proteolysis ${ }^{[14]}$ and $\mathrm{EMT}^{[32]}$, respectively. In this study, the expression of MMP-2, MMP-9, and N-cadherin in 4T1 xenograft tumor tissues were significantly decreased in the DEX-treated group, which was consistent with previous reported studies ${ }^{[11,33,34]}$. When SUL was added, the expression of MMP-2 was further suppressed, whereas that of the adhesion molecule E-cadherin, which is 
inversely related to the invasive behavior of tumor cells ${ }^{[35]}$, was significantly increased. These results indicated that MMP-2 and E-cadherin might be the most important molecules involved in the mechanism of SUL in enhancing the antimetastatic effect of DEX.

Our present study demonstrated that SUL is a promising and effective enhancer of DEX in the treatment of drugresistant and metastatic breast cancer. To verify the underlying mechanism of SUL, we added the specific D2DR agonist 7-OH-DPAT to the combination treatment of SUL and DEX in nearly all experiments except the biomarker assay with the expectation that it would neutralize the effects of SUL. As expected, the ability of SUL to enhance the effects of DEX was significantly reversed, which validated the role of SUL in antagonizing D2DR.

It is well recognized that CSCs greatly contribute to drug resistance $^{[19,36]}$ and tumor metastasis ${ }^{[37-40]}$. Combining conventional therapies with CSC-targeting therapies is of great value in the treatment of drug-resistant and metastatic can$\operatorname{cer}^{[19,40]}$. Recently, dopamine receptors (DRs) were found to be specifically expressed on the surface of CSCs, whereas limited expressed is seen on human pluripotent stem cells ${ }^{[13]}$. In addition, D2DR antagonists, such as trifluoperazine ${ }^{[12]}$ and thioridazine ${ }^{[13,14]}$, and dopamine D1-like receptor (D1DR) agonists, such as SKF $38393^{[13]}$ and dopamine ${ }^{[19]}$, have been demonstrated to have CSC suppressing activity. In this study, we demonstrated that SUL can also target CSCs. The CSC population after SUL monotherapy was significantly decreased in a dose-dependent manner both in vitro and in vivo (Figure 4). Moreover, our results showed that the proportion of CSCs in the intratumoral 7-OH-DPAT treatment group was increased relative to the control group, which may result from the stimulation of CSCs by 7-OH-DPAT. This observation was consistent with that of Sachlos et $a l^{[13]}$ and Wang et al ${ }^{[19]}$, indicating that SUL can be used as an anti-CSC agent in the combination treatment of drug-resistant breast cancer.

However, although SUL monotherapy obviously reduced the CSC population in MCF-7/Adr xenograft tumors, it did not significantly inhibit the tumor growth. SUL remarkably increased the inhibitory effect of DEX on tumor growth when it was combined with DEX. These results indicated the efficacy of SUL was achieved by CSC eradication rather than tumor growth inhibition. Similarly, in our previous study ${ }^{[19]}$, dopamine monotherapy reduced the proportion of CSCs from $11.27 \%$ (control group) to $2.56 \%$, but it did not visibly affect the growth of MCF-7/Adr xenograft tumors. However, when dopamine was co-administered with sunitinib, the inhibitory ratio of tumor size increased to approximately $95 \%$, and the proportion of CSCs was $5.05 \%$. Consistent with our results, it has been reported that other CSC-targeting drugs in monotherapy may not effectively affect tumor growth but that they can enhance the anti-cancer effects of other drugs in coadministration $^{[41]}$.

The percentage of CSCs in tumors after DEX monotherapy was increased, in agreement with previous studies that demonstrated that treatment by single chemotherapy ${ }^{[42]}$ or anti- angiogenic agents ${ }^{[43,44]}$ may increase the population of CSCs through the generation of tumor hypoxia or other underlying mechanisms. Recently, DEX was found to induce a genetic program and CCAAT/enhancer binding protein beta (CEBPB) expression in glioblastoma stem cells, which is indicative of poor survival in glioblastoma patients ${ }^{[45]}$. These reported findings might explain why the proportion of CSCs in the DEX-treated group increased and confirm the necessity of the combined use of DEX and anti-CSC agents. When DEX was combined with SUL, the proportion of CSCs significantly declined, and this effect was reversed when the specific D2DR agonist 7-OH-DPAT was added. These results suggested that the ability of SUL to enhance the effects of DEX might involve the suppression of CSC via the antagonism of D2DR.

Additionally, it has been demonstrated that CSCs play important roles in the colony formation of cancer cells ${ }^{[46]}$. The results of colony formation assays in our study support the D2DR-related mechanism because 7-OH-DPAT significantly prevented the enhancement of DEX colony formation inhibition by SUL.

Toxicity analyses in this study showed that the combination of SUL and DEX was well tolerated with little systemic toxicity or organ toxicity; only some hematotoxicity, a well-known side effect of DEX in clinical use, was seen. Despite some side effects associated with either SUL or DEX usage, no increased toxicity occurred with the combination therapy. Thus, the outcomes of this study are promising; tumor growth and metastasis were significantly suppressed for drug-resistant and metastatic breast cancer, respectively.

A limitation of this study was the lack of detailed investigations on CSC-related mechanisms. Moreover, the relationships and the underlying pathways between the suppression of D2DR and the eradication of CSCs and those between CSCs and anti-cancer effects need to be further investigated.

In summary, we demonstrated that sulpiride prominently enhanced the response to dexamethasone in the treatment of drug-resistant and metastatic breast cancer by antagonizing the dopamine D2 receptor, which might be involved in the eradication of breast cancer stem-like cells. This novel combination therapy may be useful for the clinical treatment of drug-resistant and metastatic breast cancer with low cost and high efficacy.

\section{Abbreviations}

SUL, sulpiride; DEX, dexamethasone; D2DR, dopamine D2-like receptor; D1DR, dopamine D1-like receptor; CSCs, cancer stem-like cells; MMPs, matrix metalloproteinases; ER, estrogen receptor; H\&E staining, hematoxylin and eosin staining; EMT, epithelial-mesenchymal transition.

\section{Acknowledgements}

This study was supported by the projects of the National Natural Science Foundation of China (NSFC) (Grant № 81473277, 81273583 , and 81673500). The first two authors of this article are sponsored by Pfizer. 


\section{Author contribution}

Tian-yan ZHOU, Wei LU, and Jian LI designed the research; Jian LI, Qing-yu YAO, Jun-sheng XUE, Li-jie WANG, Yin YUAN, Xiu-yun TIAN, Hong SU, Si-yuan WANG, and Wenjun CHEN performed the research; Jian LI, Tian-yan ZHOU, and Wei LU analyzed the data; and Jian LI wrote the manuscript.

\section{Supplementary information}

Supplementary information is available at the website of Acta Pharmacologica Sinica.

\section{References}

1 Siegel RL, Miller KD, Jemal A. Cancer statistics, 2015. CA Cancer J Clin 2015; 65: 5-29.

2 Gradishar WJ, Anderson BO, Balassanian R, Blair SL, Burstein HJ, Cyr A, et al. Invasive breast cancer version 1.2016, NCCN clinical practice guidelines in oncology. J Natl Compr Canc Netw 2016; 14: 324-54.

3 Nichols M. New directions for drug-resistant breast cancer: the CDK4/6 inhibitors. Future Med Chem 2015; 7: 1473-81.

4 Whyte F. Metastasis: the deadly part of cancer. Br J Nurs 1996; 5: 535-8.

5 Shajahan-Haq AN, Cheema MS, Clarke R. Application of metabolomics in drug resistant breast cancer research. Metabolites 2015; 5: 100-18.

6 Wang $\sqcup$, Li J, Hao FR, Yuan Y, Li JY, Lu W, et al. Dexamethasone suppresses the growth of human non-small cell lung cancer via inducing estrogen sulfotransferase and inactivating estrogen. Acta Pharmacol Sin 2016; 37: 845-56.

7 Yuan Y, Zhou X, Ren Y, Zhou S, Wang L, Ji S, et al. Semi-mechanismbased pharmacokinetic/pharmacodynamic model for the combination use of dexamethasone and gemcitabine in breast cancer. J Pharm Sci 2015; 104: 4399-408.

8 Gong H, Jarzynka MJ, Cole TJ, Lee JH, Wada T, Zhang B, et al. Glucocorticoids antagonize estrogens by glucocorticoid receptormediated activation of estrogen sulfotransferase. Cancer Res 2008; 68: 7386-93.

9 Egberts JH, Schniewind B, Pätzold M, Kettler B, Tepel J, Kalthoff H, et al. Dexamethasone reduces tumor recurrence and metastasis after pancreatic tumor resection in SCID mice. Cancer Biol Ther 2008; 7: 1044-50.

10 Ouatas T, Halverson D, Steeg PS. Dexamethasone and medroxyprogesterone acetate elevate Nm23-H1 metastasis suppressor gene expression in metastatic human breast carcinoma cells: new uses for old compounds. Clin Cancer Res 2003; 9: 3763-72.

11 Lin YM, Jan HJ, Lee CC, Tao HY, Shih YL, Wei HW, et al. Dexamethasone reduced invasiveness of human malignant glioblastoma cells through a MAPK phosphatase-1 (MKP-1) dependent mechanism. Eur J Pharmacol 2008; 593: 1-9.

12 Yeh CT, Wu AT, Chang PM, Chen KY, Yang CN, Yang SC, et al. Trifluoperazine, an antipsychotic agent, inhibits cancer stem cell growth and overcomes drug resistance of lung cancer. Am J Respir Crit Care Med 2012; 186: 1180-8.

13 Sachlos E, Risueño RM, Laronde S, Shapovalova Z, Lee JH, Russell J, et al. Identification of drugs including a dopamine receptor antagonist that selectively target cancer stem cells. Cell 2012; 149: 1284-97.

14 Lu M, Li J, Luo Z, Zhang S, Xue S, Wang K, et al. Roles of dopamine receptors and their antagonist thioridazine in hepatoma metastasis. OncoTargets Ther 2015; 8: 1543-52.

15 Lai EC, Chang CH, Kao Yang YH, Lin SJ, Lin CY. Effectiveness of sulpiride in adult patients with schizophrenia. Schizophr Bull 2013; 39: 673-83.

16 Rzewuska M. Sulpiride: the best known atypical, safe neuroleptic drug. Review of literature. Psychiatr Pol 1998; 32: 655-66.

17 Harada M, Bobe I, Saito H, Shibata N, Tanaka R, Hayashi T, et al. Improved anti-tumor activity of stabilized anthracycline polymeric micelle formulation, NC-6300. Cancer Sci 2011; 102: 192-9.

18 Ricardo S, Vieira AF, Gerhard R, Leitão D, Pinto R, Cameselle-Teijeiro $J F$, et al. Breast cancer stem cell markers CD44, CD24 and ALDH1: expression distribution within intrinsic molecular subtype. J Clin Pathol 2011; 64: 937-46.

19 Wang S, Mou Z, Ma Y, Li J, Li J, Ji X, et al. Dopamine enhances the response of sunitinib in the treatment of drug-resistant breast cancer: Involvement of eradicating cancer stem-like cells. Biochem Pharmacol 2015; 95: 98-109.

20 Li X, Lewis MT, Huang J, Gutierrez C, Osborne CK, Wu MF, et al. Intrinsic resistance of tumorigenic breast cancer cells to chemotherapy. J Natl Cancer Inst 2008; 100: 672-9.

21 Ji XW, Chen GP, Song Y, Hua M, Wang LJ, Li L, et al. Intratumoral estrogen sulfotransferase induction contributes to the anti-breast cancer effects of the dithiocarbamate derivative TM208. Acta Pharmacol Sin 2015; 36: 1246-55.

22 Luo KW, Yue GG, Ko CH, Gao S, Lee JK, Li G, et al. The combined use of Camellia sinensis and metronomic zoledronate in 4T1 mouse carcinoma against tumor growth and metastasis. Oncol Rep 2015; 34: 477-87.

23 Peng CT, Lin HC, Lin YJ, Tsai CH, Yeh TF. Early dexamethasone therapy and blood cell count in preterm infants. Pediatrics 1999; 104: 47681.

24 Iwanaga K, Honjo T, Miyazaki M, Kakemi M. Time-dependent changes in hepatic and intestinal induction of cytochrome P450 3A after administration of dexamethasone to rats. Xenobiotica 2013; 43: 765-73.

25 Hsieh TH, Hsu CY, Tsai CF, Chiu CC, Liang SS, Wang TN, et al. A novel cell-penetrating peptide suppresses breast tumorigenesis by inhibiting ß-catenin/LEF-1 signaling. Sci Rep 2016; 6: 19156.

26 Fan CC, Lee LY, Yu MY, Tzen CY, Chou C, Chang MS. Upregulated hPuf-A promotes breast cancer tumorigenesis. Tumour Biol 2013; 34: 2557-64.

27 Snyder KA, Hughes MR, Hedberg B, Brandon J, Hernaez DC, Bergqvist $\mathrm{P}$, et al. Podocalyxin enhances breast tumor growth and metastasis and is a target for monoclonal antibody therapy. Breast Cancer Res 2015; $17: 46$.

28 Sinha S, Khan S, Shukla S, Lakra AD, Kumar S, Das G, et al. Cucurbitacin $B$ inhibits breast cancer metastasis and angiogenesis through VEGF-mediated suppression of FAK/MMP-9 signaling axis. Int J Biochem Cell Biol 2016; 77: 41-56.

29 Mani SA, Guo W, Liao MJ, Eaton EN, Ayyanan A, Zhou AY, et al. The epithelial-mesenchymal transition generates cells with properties of stem cells. Cell 2008; 133: 704-15.

30 Thiery JP, Acloque H, Huang RY, Nieto MA. Epithelial-mesenchymal transitions in development and disease. Cell 2009; 139: 871-90.

31 Kessenbrock K, Plaks V, Werb Z. Matrix metalloproteinases: regulators of the tumor microenvironment. Cell 2010; 141: 52-67.

32 Qian X, Anzovino A, Kim S, Suyama K, Yao J, Hulit J, et al. N-cadherin/ FGFR promotes metastasis through epithelial-to-mesenchymal transition and stem/progenitor cell-like properties. Oncogene 2014; 33: 3411-21.

33 Yang JT, Lee TH, Lee IN, Chung $\mathrm{CY}$, Kuo $\mathrm{CH}$, Weng HH. Dexamethasone inhibits ICAM-1 and MMP-9 expression and reduces brain edema in intracerebral hemorrhagic rats. Acta Neurochir (Wien) 2011; 153: 
2197-203.

34 Davies S, Dai D, Pickett G, Leslie KK. Gene regulation profiles by progesterone and dexamethasone in human endometrial cancer Ishikawa H cells. Gynecol Oncol 2006; 101: 62-70.

35 Jones J, Walker R. Cell-cell and cell-stromal interactions in breast cancer invasion and metastasis (review). Int J Oncol 1997; 11: 60916.

36 Donnenberg VS, Donnenberg AD. Multiple drug resistance in cancer revisited: the cancer stem cell hypothesis. J Clin Pharmacol 2005; 45: 872-7.

37 Lawson JC, Blatch GL, Edkins AL. Cancer stem cells in breast cancer and metastasis. Breast Cancer Res Treat 2009; 118: 241-54.

38 Geng SQ, Alexandrou AT, Li JJ. Breast cancer stem cells: Multiple capacities in tumor metastasis. Cancer Lett 2014; 349: 1-7.

39 Li S, Li Q. Cancer stem cells and tumor metastasis (Review). Int J Oncol 2014; 44: 1806-12.

40 Liu H, Patel MR, Prescher JA, Patsialou A, Qian D, Lin J, et al. Cancer stem cells from human breast tumors are involved in spontaneous metastases in orthotopic mouse models. Proc Natl Acad Sci U S A 2010; 107: 18115-20.

41 Liu S, Wicha MS. Targeting breast cancer stem cells. J Clin Oncol
2010; 28: 4006-12.

42 Abubaker K, Latifi A, Luwor R, Nazaretian S, Zhu H, Quinn MA, et al. Short-term single treatment of chemotherapy results in the enrichment of ovarian cancer stem cell-like cells leading to an increased tumor burden. Mol Cancer 2013; 12: 24.

43 Chinchar E, Makey KL, Gibson J, Chen F, Cole SA, Megason GC, et al. Sunitinib significantly suppresses the proliferation, migration, apoptosis resistance, tumor angiogenesis and growth of triplenegative breast cancers but increases breast cancer stem cells. Vascular Cell 2014; 6: 12.

44 Conley SJ, Gheordunescu E, Kakarala P, Newman B, Korkaya H, Heath AN, et al. Antiangiogenic agents increase breast cancer stem cells via the generation of tumor hypoxia. Proc Natl Acad Sci U S A 2012; 109: 2784-9.

45 Luedi MM, Singh SK, Mosley JC, Hatami M, Gumin J, Sulman EP, et al. A dexamethasone-regulated gene signature is prognostic for poor survival in glioblastoma patients. J Neurosurg Anesthesiol 2017; 29: 46-58.

46 Du L, Rao G, Wang H, Li B, Tian W, Cui J, et al. CD44-positive cancer stem cells expressing cellular prion protein contribute to metastatic capacity in colorectal cancer. Cancer Res 2013; 73: 2682-94. 